OPEN ACCESS

Edited by:

Valeria Poli,

University of Turin, Italy

Reviewed by:

Andrea Graziani,

University of Turin, Italy

Clelia Madeddu

University of Cagliari, Italy

*Correspondence:

Federica Calore

federica.calore@osumc.edu

Specialty section:

This article was submitted to Molecular and Cellular Oncology,

a section of the journal

Frontiers in Oncology

Received: 29 October 2019

Accepted: 20 February 2020

Published: 04 March 2020

Citation:

Marceca GP, Londhe P and Calore F

(2020) Management of Cancer

Cachexia: Attempting to Develop New

Pharmacological Agents for New

Effective Therapeutic Options.

Front. Oncol. 10:298

doi: $10.3389 /$ fonc.2020.00298

\section{Management of Cancer Cachexia: Attempting to Develop New Pharmacological Agents for New Effective Therapeutic Options}

\author{
Gioacchino P. Marceca ${ }^{1}$, Priya Londhe ${ }^{2}$ and Federica Calore ${ }^{2 *}$ \\ ${ }^{1}$ Department of Clinical and Experimental Medicine, University of Catania, Catania, Italy, ${ }^{2}$ Department of Cancer Biology and \\ Genetics, Comprehensive Cancer Center, The Ohio State University, Columbus, OH, United States
}

Cancer cachexia (CC) is a multifactorial syndrome characterized by systemic inflammation, uncontrolled weight loss and dramatic metabolic alterations. This includes myofibrillar protein breakdown, increased lipolysis, insulin resistance, elevated energy expediture, and reduced food intake, hence impairing the patient's response to anti-cancer therapies and quality of life. While a decade ago the syndrome was considered incurable, over the most recent years much efforts have been put into the study of such disease, leading to the development of potential therapeutic strategies. Several important improvements have been reached in the management of CC from both the diagnostic-prognostic and the pharmacological viewpoint. However, given the heterogeneity of the disease, it is impossible to rely only on single variables to properly treat patients presenting this metabolic syndrome. Moreover, the cachexia symptoms are strictly dependent on the type of tumor, stage and the specific patient's response to cancer therapy. Thus, the attempt to translate experimentally effective therapies into the clinical practice results in a great challenge. For this reason, it is of crucial importance to further improve our understanding on the interplay of molecular mechanisms implicated in the onset and progression of CC, giving the opportunity to develop new effective, safe pharmacological treatments. In this review we outline the recent knowledge regarding cachexia mediators and pathways involved in skeletal muscle (SM) and adipose tissue (AT) loss, mainly from the experimental cachexia standpoint, then retracing the unimodal treatment options that have been developed to the present day.

Keywords: cancer cachexia, muscle tissue and adipose tissue loss, cachexia mediators, animal models, clinical trials, therapeutic strategies

\section{INTRODUCTION}

Cancer-associated cachexia (CC) is a paraneoplastic syndrome whose outbreak is governed and driven by inflammation. It involves various organs and is characterized by changes in body composition (1-3). Although loss of appetite is frequently associated with cancer cachexia, tissue wasting under cachectic conditions occurs through different modalities compared to those triggered by starvation, which primarily affects the adipose tissue (AT). The major feature of cachexia is, instead, represented by loss of skeletal muscle (SM) mass, not necessarily accompanied by AT wasting (4). 
Loss of muscle mass in cachectic individuals is due to altered proteostasis, which results from a combination of enhanced proteolysis and decreased protein synthesis $(5,6)$. Here, the high rate of proteolysis largely depends on upregulation of ubiquitinproteasome and autophagy-lysosomes pathways, while calpains and caspases have been found to contribute to a lesser extent, though valuably. For instance, the calpains-mediated protein degradation is thought to act upstream of the ubiquitinproteasome pathway, thus allowing the release of myofilaments from the myofibrils and their subsequent ubiquitylation and degradation (7).

Patients with CC often manifest generalized hypermetabolism with lower energy intake and higher energy expenditure. In particular, anomalous increases in resting energy expenditure (REE) are nowadays considered the major contributor to energy consumption. In this context, systemic inflammation and changes in the immune system both represent important determinants of this condition, albeit the precise mechanisms remained elusive $(8,9)$. Increases in energy expenditure are also explained by enhanced thermogenesis and "browning" of white adipose tissue (WAT), which consists of a rapid increase of beige adipocytes $(10,11)$. Moreover, WAT of cachectic individuals can undergo to consistent dissolution of fatty acids and glycerol. Such an event seems to occur in consequence to increased lipolytic activity of adipose triglyceride lipase (ATGL) and hormonesensitive lipase (HSL), two key enzymes involved in catabolism of triglycerides. On the contrary, some studies suggest that no significant downregulation in lipogenesis or expression/activity of lipoprotein lipase (LPL) occur in patients with CC $(12,13)$.

Incidence and prevalence of CC are not homogenous across cancer patients, but they rather vary depending on the tumor type and stage. CC has been mainly associated with incurable cancers and is highly prevalent at the end of life $(14,15)$; however, it can also occur in curable cancers and may be reversed by properly treating the underlying tumor (16). Meanwhile, this syndrome is notoriously influenced by additional endogenous and environmental factors, such as comorbidities, genetic risk factors, sex, age, and anti-cancer treatment (17-19). A report based on information provided by two independent studies showed a prevalence of $\sim 70 \%$ for pancreatic cancer, $\sim 60 \%$ for gastro-esophageal and head-neck cancers, and 50-40\% for non-small-cell lung cancer, colorectal cancer, and certain hematological malignancies (20). Similarly, a recent systematic review (15) reported very high risk (80-90\%) of developing cachexia for patients with liver, pancreatic and lung cancers, followed by head-neck, gastric and colorectal cancers (60-70\%). On the contrary, patients with thyroid, breast and prostate cancers and melanoma of the skin represented the groups at lowest risk $(\sim 20 \%)$. In the same study, cachexia was defined for the first time an orphan disease (15).

Approximately $20-30 \%$ of mortalities in cachectic tumor patients are thought to derive from cachexia rather than from the tumor burden itself $(6,21)$. In addition, cachexia can lead to lower responsiveness to anticancer therapies, worsening of life quality and poor prognosis in advanced tumor patients $(14,22,23)$. In this regard, it has been reported that treating cachectic patients with conventional chemotherapeutic regimens further enhances hypercatabolism of SMs and could cause changes in fat and bone mass. This would exacerbate the pathological condition, thus requiring dosage limitation or therapy interruption (3).

Clinically, combinations of metastatic tumor, muscle wasting, debilitation, and refractoriness to chemotherapy seriously limit benefits from treatments of cachexia, even when multimodal options are adopted. Thus, the identification of reliable diagnostic markers, predictive of CC, is of fundamental importance to prevent the patient's physiological decline. According to the most recent consensus report, published by Fearon et al., the current standard diagnostic criterion for cachexia is represented by a weight loss $>5 \%$ over the past 6 months, or any degree of weight loss $>2 \%$ in individuals showing a Body Mass Index (BMI) $<20$ or sarcopenia (14). In the same report, a classification criterion was proposed to clinically subdivide CC into three stages, aiming to properly treating cachectic tumor patients. In line with the diagnostic criterion, such classification would be based on three established parameters of cachexia, i.e., percentage of weight loss, BMI values and metabolic changes (14). Specifically, patients manifesting anorexia, impaired glucose tolerance and weight loss $\leq 5 \%$ over the past 6 months would be classified as pre-cachectic. Patients with systemic inflammation, BMI $<20$, weight loss $>$ $5 \%$ over the past 6 months and ongoing weight loss of more than $2 \%$ would be classified as cachectic. Absence of responsiveness to anticancer treatments or preterminal cancer stage would instead determine refractory cachexia (14). However, this classification cannot currently be given as officially accepted by clinicians, but is rather to be considered as a proposal under evaluation. Indeed, additional diagnostic parameters such as hemoglobin $(\mathrm{Hb})$ and albumin levels were previously proposed (4). The same parameters were then re-evaluated by two more recent studies, with the addition of $\mathrm{C}$ reactive protein levels $(24,25)$. However, none of these were included in the diagnostic definition of CC neither in its classification by the last consensus, although it was stated that several other components of cachexia (thus including the aforementioned ones) should be further evaluated (14).

Interestingly, some research groups investigated on possible causative genetic variants underlying CC or cachexia-related appetite loss in cancer patients [e.g., $(26,27)]$. Although these studies put into evidence dozens of single nucleotide polymorphisms as potentially involved in such processes, no significant findings were brought out. Moreover, some discrepancies emerged when results from some of these studies were compared to one another (26). Nonetheless, a role for genetics in the pathophysiology of CC cannot be excluded, since it should be considered that this type of analysis is in its early stage. Thus, further genome-wide approaches are needed, considering the complexity and the variability of the syndrome.

From the molecular standpoint, numerous in vitro and in vivo studies have demonstrated that several pro-inflammatory cytokines, toll-like receptors (TLRs) and growth/differentiation factors (GDFs) act as mediators of CC. In general, most of these molecules are purposely used as signaling molecules in cell-to-cell communication and mechanisms involved in innate immunity, and exert pleiotropic effects. For instance, cytokines are primarily produced by immune cells, although several other cells of the organism as well as tumor cells are capable to express 
them (28). In the pathogenesis of cancer, the tumor-induced inflammatory response leads to expression and secretion of a number of immune-suppressive and pro-inflammatory cytokines by immune cells, aiming to eradicate tumor cells from the host (29). However, inappropriate accumulation/regulation of leukocytes in the tumor site can cause an imbalance between pro- and anti-inflammatory mechanisms, eventually leading to chronic inflammation and subsequent immunosuppression (30), as occurs in advanced cancer patients. As a result, the chronic presence of such mediators of inflammation in both the tumor microenvironment and circulation causes systemic deregulations and metabolic dysfunctions in the host, including CC $(2,29)$.

\section{MEDIATORS OF CC: WHAT HAVE WE LEARNED FROM IN VITRO AND IN VIVO STUDIES}

Experimental research on CC has experienced an exponential increase in terms of gained knowledge during the last three decades. In particular, the identification of several endogenous factors functioning as mediators of $\mathrm{CC}$ and the uncovering of their relative mechanisms of action has led to the achievement of important frontiers in this field of oncology. This has allowed the development of potential effective pharmacological agents for the clinical management of this metabolic syndrome (31). Intriguingly, we now know that several of these effectors share the same or similar metabolic effects, and that most often they exhibit synergic effects when administered together. Moreover, most of them are simultaneously involved in both SM and AT depletion, though exerting a distinct role depending on the target tissue (see next section).

\section{Tumor Necrosis Factors}

Tumor necrosis factor alpha (TNF $\alpha$, also known as cachectin) has long been shown to play a role in murine models of CC $(32,33)$. Albeit normally involved in acute phase reaction triggering and apoptosis, $\mathrm{TNF} \alpha$ can also promote tumorigenesis and metastasis, and has been shown to act as an autocrine growth factor for various tumor types (34). Early studies showed that TNF $\alpha$ had the ability to inhibit differentiation of both skeletal myocytes and adipocytes $(35,36)$, while it caused reduced protein content and higher degradation of myofibrillar proteins in differentiated skeletal myocytes, in a time- and dose-dependent manner (37, 38). However, later experiments demonstrated that $\mathrm{TNF} \alpha$ alone was not sufficient to cause a significant dysfunction of skeletal myofibers in differentiated myocytes, but a synergic action with other cytokines, such as interferon gamma (INF $\gamma$ ), was required to produce valuable effects [e.g., $(35,39)]$. More recent studies have reported similar results for a structural homolog of $\mathrm{TNF} \alpha$, i.e., TNF-related weak inducer of apoptosis (TWEAK, also known as TNFSF12), which presents overlapping signaling functions with the former $(40,41)$.

\section{Interleukins}

Some of the cytokines belonging to the class of interleukins (ILs) have been shown to significantly contribute to tumor growth and CC. First and foremost, circulating interleukin-6 (IL-6) is recognized as one of the main factors leading to the outbreak of cachexia. For instance, significant concentrations of IL-6 were detected in the serum of cachectic mice transplanted with a cachexia-inducing colon-26 adenocarcinoma (C26) subtype, where serum level of IL-6-but not that of TNF $\alpha$-correlated with severity of the pathological status (42). Yet, high constitutive levels of circulating IL- 6 caused suppression of muscle protein synthesis at the initial stage of cachexia in a different murine model (43). On the contrary, attenuation of the IL-6 signaling was shown to abolish key features of CC $(42,44)$, although such inhibition was not sufficient to reverse the process (43). In a similar manner, it has been evidenced a role for IL- 6 in induction of energy expenditure and loss of fat mass by promotion of WAT browning. In fact, the knock-out of IL-6R in cachectic mice transplanted with B16 melanoma cells showed partial though significant reduction of WAT browning when compared with control mice (11). At the same extent, the genetic blockade of IL6 was found to be critical in a syngeneic graft model with C26 cancer cells, as it prevented WAT browning and cachexia (11).

Leukemia inhibitory factor (LIF) is another IL-6 family member, involved in a variety of distinct biological processes including inflammation, cell growth, differentiation, neural development, and hematopoiesis $(45,46)$. As in the case of IL-6, LIF was previously reported to induce muscle wasting in various animal models $(47,48)$. A recent study further demonstrated the involvement of tumor-secreted LIF in myotube atrophy in a C26 cancer-induced cachexia model (49). Here, elevated circulating levels of this interleukin induced expression of atrophy-related genes. On the contrary, immunological blockage of circulating LIF prevented the triggering of such phenomenon (49). LIF has recently been shown to be implicated in cachexiaassociated lipolysis as well (50), whereby interaction between this interleukin and its cognate membrane receptor LIFR- $\alpha$ caused enhanced expression of genes involved in lipids catabolism. Interestingly, the same study revealed a double mechanism of action for LIF, since it sustained fat mass loss through an equal combination of peripheral (i.e., directly exerted on adipocytes) and central (i.e., exerted on the hypothalamus) contributions. In particular, the latter mechanism of action was counterbalanced by leptin signaling (50).

Similarly, to IL-6, IL-1 alpha (IL-1 $\alpha$ ) was initially evidenced as a factor capable to induce protein breakdown in isolated SM during systemic inflammation (51). Administration of IL$1 \alpha$ was found to induce cachexia together with anorexia by causing accelerated SM protein wasting in a rat model (52). Accordingly, the pharmacological blockade of IL-1 $\alpha$ receptor reduced tumor growth and slowed down the development of CC in methylcholanthrene-induced sarcoma (MCG 101)-bearing mice (53).

A more recent study demonstrated how IL-1 beta (IL$1 \beta$ ) increased SM catabolism in a rodent model of CC by promoting a cachexia-associated gene expression pattern in the hypothalamic-pituitary-adrenal (HPA) axis, differently from IL-6 and IL-1 $\alpha$ (54). Few other studies on experimental cachexia have raised the possibility for other interleukins to be involved in the onset of cachexia, as is the case of IL10 and homodimeric IL-12 (55), although with a lesser extent of evidence. 


\section{Interferon Type II}

INF $\gamma$, the only member of the type II class of interferons, has a critical role in innate and adaptive immunity against viral infections, promotes activation of macrophages and exerts mild antiproliferative effects on certain cell types (56). Nonetheless, several studies have reported a role for this cytokine in enhancement of tumor growth, metastasis $(57,58)$ and development of CC (59). Nude mice injected with genetically engineered ovary tumor cells $(\mathrm{CHO})$ producing murine IFN- $\gamma$ developed severe cachexia, contrary to those inoculated with the parental tumor cell line (60). Accordingly, when mice injected with $\mathrm{CHO} / \mathrm{INF} \gamma$ cells were treated with anti-INF $\gamma$ monoclonal antibodies, development of cachexia was prevented (60). In line with this, early or late treatment of Lewis lung carcinoma (LLC)bearing mice with anti-INF $\gamma$ monoclonal antibodies was shown to counteract progression of cachexia (61). Importantly, both of these studies reported that here AT, but not SM, was the main target of INF $\gamma(60,61)$.

\section{MicroRNAs}

Over the last decade, several proofs were gained about the involvement of non-coding RNAs, in particular microRNAs (miRNAs), in loss of lean and fat mass under cachectic conditions. In their mature form, miRNAs are $\sim 21-23$ nucleotides in length and exert a well-recognized role in gene regulation. In particular, miRNAs have been extensively studied as biomarkers for histological classification, disease prognosis, clinical response to treatments and diagnosis of cancer $(62,63)$. Besides exerting their action within the cell, miRNAs can be released into extracellular fluids and are referred to as extracellular or circulating miRNAs. At the same extent of intracellular miRNAs, circulating miRNAs are capable to modulate gene expression in recipient cells, determining, adjusting or deregulating cells' physiological status (64). Moreover, secreted miRNAs can have a role in cell-to-cell communication [e.g., $(65,66)]$. As CC mediators, miRNAs seem to exert their action by favoring cell apoptosis, protein degradation, or causing downregulation of anabolic processes. For instance, circulating miR-203a-3p secreted by metastatic human colorectal cancer contributed to exacerbation of myopenia in pre-operative cancer patients by targeting survivin (BIRC5), a negative regulator of caspase-dependent apoptosis (67). MiR-21-5p and-206, instead, played an important role in the onset of muscle atrophy in mice under distinct muscledebilitating conditions, including CC. This was due to the miRNA-mediated inhibition of the translational initiator factor eIF4E3 and transcription factor Yin Yang 1 (YY1), involved in mitochondrial biogenesis (68). Yet, mir-155-5p secreted by human breast cancer cells was proven to promote WAT browning and increased BAT thermogenesis but not lean mass loss. This was due to the targeting of peroxisome proliferatoractivated receptor gamma (PPAR $\gamma)$, a well-known regulator of glucose metabolism and fatty acid storage (69).

\section{Toll-Like Receptors}

Toll-like receptors (TLRs) are other essential components of the innate immune response. TLRs are present either on the cell surface or in endosomes, and are capable to interact with microbial components, danger-associated self molecules or non-self nucleic acids presenting well-defined patterns. Once stimulated by such interactions, TLRs activate two possible signaling pathway leading to downstream immunogenic gene expression (70). One recent study has evidenced differential expression of TLR genes in cachectic LLC-bearing mice compared to non cachechtic controls (71). Moreover, results from the same study suggested that increased expression of TLRs mRNA may depend on factors secreted by tumor cells, and that different tumors, such as LLC and C26, are likely to induce distinct pattern of TLR expression.

Among TLRs, TLR4 belongs to the cell-surface group and is well-known to possess high affinity for lipopolysaccharide (70). TLR4 was initially shown to act as a master regulator of inflammatory muscle catabolism, as its exposition to lipopolysaccharide caused significant loss of myofibrillar proteins and mitochondria in both cultured and in vivo murine muscle cells (72). Later, this receptor was demonstrated to be directly implicated in myotube atrophy in LLC-bearing mice, causing cachexia. In this murine model, activation of TLR4 was caused by cellular uptake of high levels of heat shock protein 70 (Hsp70) and Hsp90, secreted by tumor cells through extracellular vesicles (EVs) (73). In turn, activation of TLR4 correlated with evident muscle wasting and increased levels of circulating TNF $\alpha$ and IL6 (73). TLR4 was also reported to be involved in remodeling of AT in LLC-bearing mice. In fact, it was demonstrated that either genetic ablation or pharmacological inhibition of TLR4 in cachectic mice caused suppression of adipocytes atrophy and also reduced macrophage infiltration into the AT (74).

TLR7/8 is mainly located at the endosomal level and recognizes viral single-stranded RNA molecules (70). TLR7/8 was found to have a significant impact in experimental CC after being activated by EV-derived cargo. Specifically, our group demonstrated that murine TLR7 was capable to interact with EV-derived miR-21-5p secreted by lung and pancreatic cancer cells. Once activated, TLR7 induced muscle loss by promoting apoptosis in cultured myocytes in a JNK-dependent manner. On the contrary, myocytes from TLR7 ${ }^{-/}$LLC-bearing mice showed significantly reduced cell death (66). Recent experiments confirmed these results (75) and demonstrated that also tumorsecreted miR-29a-3p was capable to interact with murine TLR7, inducing cell death even with higher effectiveness than miR-21$5 \mathrm{p}$ (75).

A role in development of cancer cachexia has been recently suggested for TLR5 as well (76). In fact, activation of this receptor, which is expressed on the plasmatic membrane of certain gastric cancer cells, seemed to contribute to the onset of CC, possibly due to TLR5-mediated overexpression of LIF (76).

\section{Cytokines of the Transforming Growth Factor $\beta$ Superfamily}

Besides pro-inflammatory cytokines and TLRs, regulatory proteins belonging to the transforming growth factor $\beta$ (TGF $\beta$ ) superfamily of cytokines have been identified as potential actors exacerbating SM atrophy in cachexia. Among these, Myostatin 
(Mstn) and Activin A (ActA) present a partial overlap in their signaling function, since both are capable to interact with either of the Activin type II receptors (ActRIIA or ActRIIB), expressed on the surface membrane of skeletal myocytes (77). Mstn (also known as GDF8) is primary synthesized by SM cells and functions as an autocrine factor causing a strong downregulation of myogenesis $(78,79)$, while inhibition of its expression/function leads to a dramatic increase in muscle mass $(80,81)$. Following this line, later studies demonstrated that Mstn mRNA expression levels increased up to $\sim 50 \%$ in experimental models of CC, while expression levels of $\mathrm{MyoD}$, a myogenic transcription factor indispensable for myoblast fusion and SM development, decreased of $\sim 45 \%$ in comparison with controls $(82,83)$. In contrast, when synthetized antisense RNA oligonucleotides were used to target the Mstn mRNA in vivo, expression levels of both Mstn and MyoD tended to revert toward the normal phenotype, and led to a significant increase in muscle mass (83).

Differently from Mstn, ActA is expressed by a variety of cell types, has a wide range of regulatory functions and is negatively modulated by several factors including Inhibin (Inhb) and Follistatin (FS) (84). In the context of muscle wasting, concentrations of circulating ActA seem to be particularly increased during acute inflammation or in certain metastatic cancers $(85,86)$. Since ActA can reproduce the biological action of Mstn by binding to the ActRII receptors, knockdown experiments for Inhb caused dramatic loss of both lean and fat mass in mice, leading to death (87). Similarly, increase of local or circulating concentrations of ActA induced by direct methods caused muscle atrophy in treated mice (88). On the contrary, the pharmacological blockade of ActRIIB or administration of its soluble decoy forms (sActRIIB) in multiple rodent models of CC reversed atrophy of skeletal and cardiac muscles and prolonged survival of treated mice, albeit it had no effects on tumor growth or loss of AT $(87,89)$.

\section{Parathyroid Hormone-Related Peptide}

Two recent works highlighted the role of parathyroid hormonerelated peptide (PTHrP) in WAT browning under cachectic conditions $(10,90)$. Besides being expressed in kidney and bone (91), PTHrP can be overexpressed by many tumor types and acts as an endocrine effector capable to induce thermogenic gene expression in adipocytes. Moreover, its presence in the circulation correlates with a greater degree of wasting in individuals with metastatic cancer (10). PTHrP induced thermogenesis and hypermetabolism of the AT in a murine model of LLC. The evidence was given by the fact that treatment with PTHrP antibodies strongly prevented the tumor-induced AT browning in comparison to the control group (10). In addition, treatment with PTHrP antibodies also impaired LLC tumor-induced muscle wasting, atrophy of muscle fibers, and atrophy-related gene expression in treated mice (10). In a later study, the same research group corroborated the previous results demonstrating a key role for the PTHrP receptor (PTHR) in triggering browning and thermogenesis following the binding to its ligand (90). Mice knockout for PTHR in their fat tissue were resistant to cachexia driven by the LLC tumor.

\section{Adipokines}

Zinc- $\alpha 2$-glycoprotein (ZAG) is an adipokine functioning as a lipid mobilizing factor (LMF). ZAG is usually expressed by differentiated adipocytes (92), albeit it was reported that other tissues express it as well (93), including several cancer cells (94). ZAG expression has been reported to be markedly elevated in AT of mice transplanted with cachexia-inducing tumor (93), whereby this phenomenon has been positively correlated with increased lipolysis and subsequent fat loss $(95,96)$. As a counterevidence, knockout of ZAG caused significant increases in bodyweight of mice fed with standard or lipid-rich diet when compared with wild-type controls. Similarly, the same group of ZAG-deficient mice showed significant decrease in adipocyte lipolysis in response to treatment with agents that increase cAMP (97). One study carried out on cachectic patients with gastrointestinal cancer showed that ZAG is primarily produced and secreted by WAT, and correlates with nutritional status in both malignant and nonmalignant conditions. However, it seems that neither WAT nor tumor cells secretory activity lead to significant increases of circulating levels of this adipokine. Thus, ZAG should be considered as a lipolysis-promoting factor locally produced (94).

\section{PUTTING PIECES TOGETHER: PATHWAYS UNDERLYING CC}

\section{Dysregulated Pathways in SM}

From a systematic standpoint, all the aberrant metabolic features characterizing CC are caused by activation of few distinct signaling pathways, triggered by the interaction between the aforementioned mediators and their cognate receptors.

Under normal conditions, myofibrils, the main structural components of myocytes, physiologically undergo to a balanced protein turnover. Under cachectic conditions, instead, excessive rates of myofibril breakdown and low rates of protein synthesis are typically observed in patients' SM, resulting in muscle weakness, fatigue, reduced tolerance to chemotherapy and low quality of life (QoL) $(1,3)$. Here, the ubiquitin-proteasome pathway, which takes part in breakdown of short-lived and regulatory proteins, is known to play a relevant role (98). As its name suggests, this proteolytic pathway is essentially dependent on the presence of active enzymes involved in protein ubiquitylation, which include the well-known family of E3 ubiquitin ligases. Among these, muscle RING fingercontaining protein 1 (MURF1, also known as TRIM63) and muscle atrophy $\mathrm{F}$ box protein (MAFbx, also known as Atrogin1) are defined as muscle-specific E3 ubiquitin ligases and are the most widely studied in the case of cachexia-associated muscle loss. Both these enzymes mediate myofibrillar protein breakdown by acting on several components of the sarcomeric thick filament, including myosin heavy chain (MHC), and are thought to interfere with processes related to protein synthesis (99). The proinflammatory cytokines TNF $\alpha$, TWEAK and IL-1 have been shown to cause increased expression of both these E3 ubiquitin ligases via the nuclear transcription factor kappa $\mathrm{B}$ (NF-

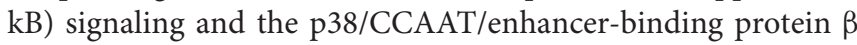


(p38/C/EBP $\beta$ ) pathway, respectively $(35,41,100)$. Activation of the NF-kB signaling was reported to cause overexpression of paired box 7 (PAX7) in myocytes (101). The latter is a transcription factor playing an essential regulatory role in myogenesis, being responsible for repression of $\mathrm{MyoD}$ and myogenin transcriptional activity. In line with this, it has been demonstrated that NF- $\mathrm{B}$-dependent upregulation of PAX7 impairs the regenerative ability of myogenic cells and drives toward muscle wasting under tumor conditions (101).

A different signaling pathway is instead activated by IL6. In particular, this interleukin signals via its membrane receptor IL-6R, which in turn forms a heterodimer with its transducing subunit (gp130). This leads to activation of the Janus kinase/signal transducer and activator of transcription (JAK/STAT) pathway, with subsequent translocation of activated STAT3 into the nucleus. This event contributes to the regulation of expression of the E3 ubiquitin ligases and autophagy genes (102). STAT3 also induces expression of $\mathrm{C} / \mathrm{EBP} \delta$, a transcription factor that promotes expression of Mstn under cachectic conditions (102). Indeed, a recent work revealed that, at the same extent of IL-6, TNF $\alpha$, and INF $\gamma$ synergistically activate STAT3 by promoting its JAK-mediated phosphorylation independently from IL-6 (103). This demonstrates that NF-kB and STAT3 both respond to the same upstream signaling, and thus cooperate amplifying the signal and promoting expression of pro-cachectic genes.

Although the precise mechanism have remained elusive, it is known that proinflammatory cytokines also suppress activity of the RAC serine/threonine-protein kinase (AKT), which is downstream of insulin signaling and central to many cellular processes. AKT negatively modulates the transcriptional activity of forkhead box protein $\mathrm{O} 1$ (FoxO1) and FoxO3, which control the expression of genes involved in metabolic homeostasis, including that of MURF1 and MAFbx $(104,105)$. In particular, under physiological conditions, AKT phosphorylates the FoxOs proteins, preventing their nuclear translocation. Moreover, AKT inhibits activity of tuberous sclerosis complex 2 (TSC2), a main inhibitor of the mammalian target of rapamycin complex 1 (mTORC1), which is notoriously involved in functions like protein synthesis, pentose anabolism and blockage of autophagy (106). To the contrary, cytokine-mediated suppression of AKT causes downregulation of mTORC1 activity and favors FoxOs dephosphorylation and nuclear location, thus promoting miofibrillar degradation $(107,108)$. Interestingly, it was recently reported that FoxOs also induce expression of a third musclespecific E3 ubiquitin ligase, termed specific of muscle atrophy and regulated by transcription (SMART) (108).

One further negative regulator of $\mathrm{FoxO} 3$ is the peroxisome proliferator-activated receptor gamma coactivator 1-alpha (PGC1 $\alpha$ ), a master regulator of mitochondrial biogenesis and transcriptional coactivator regulating expression of genes involved in energy metabolism (109). PGC1 $\alpha$ was demonstrated to be downregulated in muscles of cachectic tumor-bearing mice, while its transgenic expression allowed muscle recovery in vivo (109).

Aberrant activation of signaling pathways downstream of TLRs is also known to contribute to cancer progression and overproduction of proinflammatory cytokines underlying cachexia (110). Some studies demonstrated that the notorious TLR/myeloid differentiation factor 88 (TLR/MyD88) signaling (70) mediates skeletal muscle wasting during CC $(71,111)$. Previous studies suggested that the mechanism involved in such phenomenon is the TLR/MyD88-mediated activation of NF-kB signaling (112-114). Indeed, in vivo experiments carried in a recent work partially confirmed such hypothesis by demonstrating that ablation of MyD88 in LLC-bearing mice inhibited tumor-induced activation of NF-kB in SMs (71). However, the authors showed that most of muscle mass loss in this murine model was due to activation of the TLR4/MyD88/inositol-requiring protein $1 \alpha$ (IRE1 $\alpha) / \mathrm{X}$-boxbinding protein 1 (XBP1) axis. Both IRE1 $\alpha$ and XBP1 are linked to the unfolded protein response signaling, which is activated following accumulation of misfolded proteins or dysregulations in calcium levels within the SM. In particular, the spliced form of the transcription factor XBP1 was demonstrated to be a potent promotor of expression of proinflammatory cytokines and autophagy-related genes, while its ablation resulted in significant attenuation of loss of lean mass both in vitro and in vivo. Importantly, the authors showed that this mechanism is likely to involve not only TLR4, but also some other TLRs, including TLR7 (71).

Through their binding to ActRII receptors, TGF $\beta$-family members like Mstn and ActA promote protein degradation via $\mathrm{p} 38 / \mathrm{JAK}$-mediated phosphorylations and activation of small mother against decapentaplegic (SMAD) signaling (115). In particular, it is known that, in the case of myoblasts and myocytes, Mstn specifically interacts with the ActRIIB receptor, subsequently inducing the assembly of type-I receptor ALK4. This in turn leads to activation of the SMAD2/3/4 complex $(115,116)$. Once assembled, the SMAD complex is translocated to the nucleus and acts as a transcription factor favoring expression of genes related to protein degradation and inhibiting that of genes involved in protein synthesis and proliferation (115).

As previously stated, other important pathways are involved in cachexia-associated muscle loss. Among these, pathways of autophagy certainly represent other important and widely activated mechanisms that underly protein breakdown in CC. However, such pathways are far less characterized than those related to ubiquitin-proteasome pathway. Some studies showed that markers of autophagy like Beclin-1, (an indicator of autophagy induction), p62 (a marker of lysosomal degradation) and the two forms of microtubule-associated proteins $1 \mathrm{~A} / 1 \mathrm{~B}$ light chain $3 \mathrm{~B}$ protein (LC3B-I and LC3B-II, used to measure autophagosome abundance) are overexpressed in SM of tumorbearing animals and cancer patients (117-120). However, in spite of the increased autophagic production and activity, the findings gained so far showed impairment of autophagosome clearance in the muscle of cancer hosts, suggesting that the process of lysosomal degradation does not come to complete cargo degradation $(117,119,120)$. A further interesting finding was the phosphorylation and subsequent activation of Unc-51 like autophagy activating kinase 1 (ULK1), a driver of autophagy, in SMs of cachectic mice (121). Such an event was suggested to be mediated by upstream activation of $\mathrm{p} 38$, which was previously 


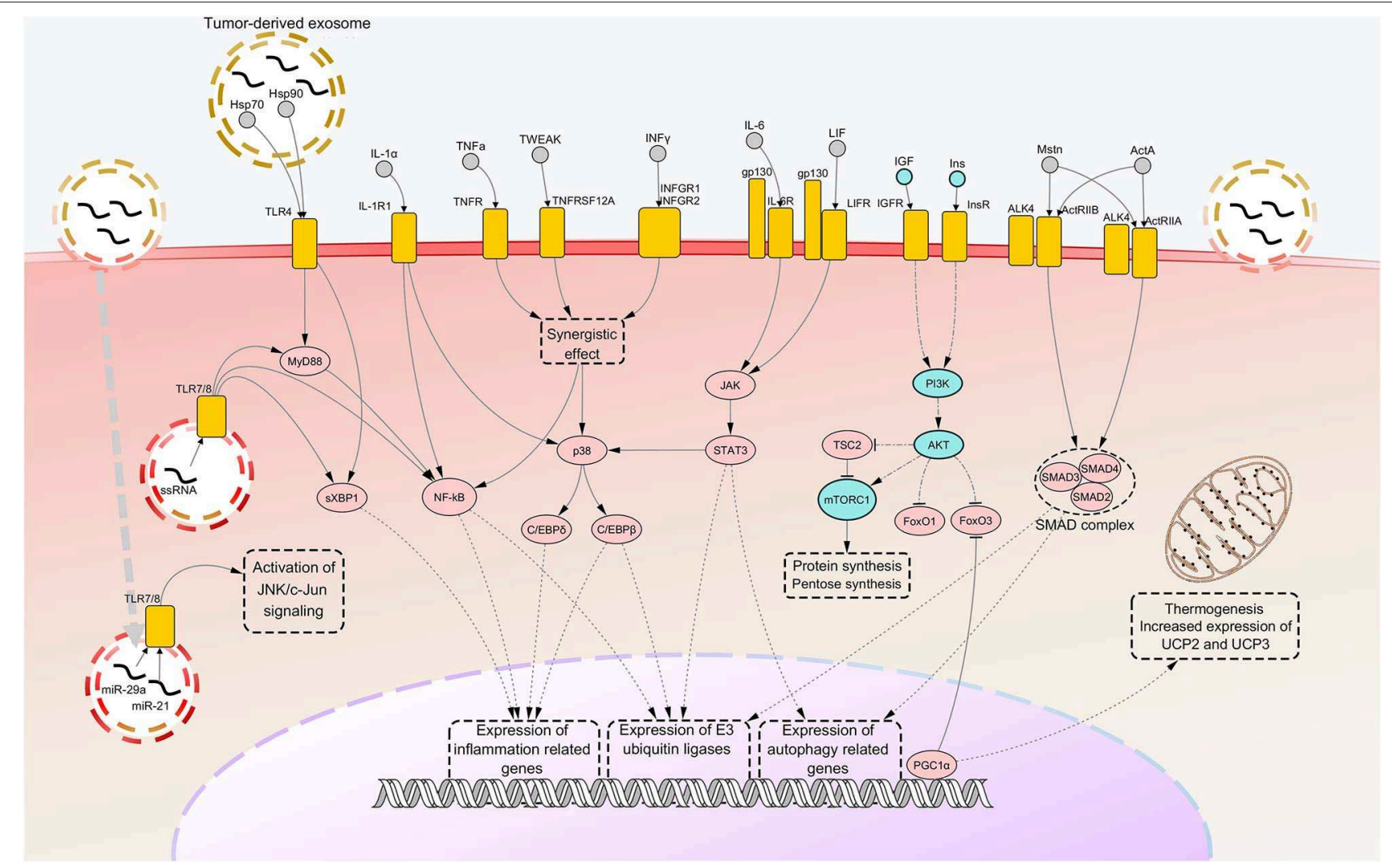

FIGURE 1 | Notorious molecular mechanisms underlying skeletal muscle wasting during cancer cachexia. Atrophy of skeletal muscle in cancer cachexia is due to aberrant activation of specific signaling pathways, consequent to the binding of factors secreted by the tumor, the stroma or the immune system to their cognate receptors. Most of such signaling pathways converge toward activation of selective transcription factors, causing their nuclear translocation and binding to promoters of cachexigenic genes. These include genes encoding cytokines [e.g., tumor necrosis factor alpha (TNF $\alpha$ ) and interleukin 6 (IL-6)], inflammation-related receptors [e.g., toll-like receptor 4 (TLR4) and TLR7], myokines [e.g., myostatin (Mstn)], muscle-specific E3 ubiquitin ligases and autophagy-related proteins. Such events potentiate inflammatory processes at the local level and cause the breakdown of myofibrillar proteins, impairing the contractile function of skeletal muscles. Several cachexia-inducing factors are known to exert their cachectigenic effect by acting synergistically, as in the case of TNF $\alpha$ and interferon gamma (INF $\gamma$ ). To the contrary, downregulation occurring in the insulin (Ins) and insulin growth-like factor (IGF) signaling determines a decrease in mTOR-dependent protein synthesis, due to upstream downregulation of RAC serine/threonine-protein kinase (AKT) activity. In normal conditions, AKT functions also as a negative regulator of forkhead box protein $\mathrm{O} 1$ (FoxO1) and FoxO3 transcription factors, preventing their nuclear translocation. Thus, consequent to AKT downregulation under cachectic conditions, both these FoxOs localize into the myonucleus and induce transcription of autophagy components and muscle-specific E3 ubiquitin ligases.

Peroxisome-proliferator-activated receptor-gamma co-activator 1-alpha ( $\mathrm{PGC1} 1 \alpha)$, overexpressed during cancer cachexia, is known to inhibit FoxO3 binding to the DNA and cause enhance expression of genes involved in energy metabolism and mitochondrial biogenesis. Upregulated nodes are colored in pink and connected with other nodes through continuous edges. Downregulated nodes are colored in azure and connected with other nodes through dash-dot edges. Dashed edges represent connections between transcriptional/co-transcriptional factors and gene expression. ActA, activin A; ActllR, activin type 2 receptor; ALK4, activin receptor type-1B; C/EBP, CCAAT/enhancer binding protein; C-Jun, proto-oncogene c-Jun; Gp130, glycoprotein 130; Hsp, heat shock protein; IL-1a, interleukin 1 alpha; IL-1R1, interleukin 1 receptor 1; IL-6R, IL-6 receptor; INFGR, INFy receptor; JAK, Janus kinase; JNK, C-Jun N-terminal kinase; LIF, leukemia inhibitory factor; LIFR, LIF receptor; miR, microRNA; mTORC1, mammalian target of rapamycin complex 1; MyD88, myeloid differentiation factor 88; NF-kB, nuclear transcription factor kappa B; p38, p38 mitogen-activated protein kinase; PI3K, Phosphoinositide 3-kinase; SMAD, small mother against decapentaplegic; STAT3, signal transducer and activator of transcription 3; sXBP1, spliced isoform X-box-binding protein 1; TNFR, tumor necrosis factor receptor; TNFRSF12A, TNF Receptor Superfamily Member 12A; TSC2, tuberous sclerosis complex 2; TWEAK, TNF-related weak inducer of apoptosis; UCP, uncoupling protein.

reported to cause activation of $\mathrm{C} / \mathrm{EBP} \beta$. The molecular pathways involved in SM atrophy are depicted in Figure $\mathbf{1 .}$

\section{Dysregulated Pathways in AT}

To date, knowledge about pathways involved in loss of AT under cachectic conditions is markedly less detailed than that available for loss of SM. However, it is now widely recognized that excessive degradation of fatty acids and energetic imbalance in AT can contribute to the destructive impact of cachexia on tumor hosts.

Under physiological conditions, AT lipolysis is an essential catabolic process that provides lipids and energy to tissues and organs following opportune stimulations. In particular, this process occurs after interaction between certain molecules (including $\beta$-adrenergic neurotransmitters) and their cognate G-protein-coupled receptors (GPCRs) expressed in adipocytes. Downstream of this event, a number of adenosine 
triphosphate (ATP) molecules are converted to cyclic adenosine monophosphate (cAMP) by GPCRs-stimulated adenylyl cyclases. Increased levels of cytosolic cAMP eventually lead to activation of protein kinase A (PKA) by phosphorylation, which in turn leads to phosphorylation of both HSL and perilipin-1, a protein acting as a protective coat for lipid droplets. This implies activation of HSL and its translocation to the surface of lipid droplets, resulting in greater access to triglycerides and enhanced lipolysis $(12,13)$. ATGL represents another key point of the lipolytic process, since its enzyme kinetics determines the rate limiting of triglycerides catabolism. Specifically, ATGL is mainly responsible for the first step of triglycerides hydrolyzation, which leads to the release of a single fatty acid and diacylglycerol (DAG). The other two steps of lipolysis are then completed by HSL and monoacylglycerol lipase (MGL), respectively (12).

Under conditions of chronic systemic inflammation, several events are known to occur affecting the AT metabolism, including suppression of appetite, enhancement of lipolysis and inhibition of LPL (122). The latter, in particular, has a dual function, being involved in receptor-mediated lipoprotein uptake and degradation, and hydrolysis of serum triglycerides in non-esterified fatty acids and 2-monoacylglycerol for tissue utilization. LPL deficiency leads to hypertriglyceridemia, while its upregulation causes insulin resistance and can promote obesity (123). Nonetheless, results from some studies clearly indicate that depletion of triglycerides in cachectic individuals is not due to impairments in LPL activity nor in lipogenesis, but depends on an increase in lipolysis, confirmed by high expression rates of HSL $(124,125)$.

Among procachectic cytokines, TNF $\alpha$ was shown to cause increased levels of phosphorylated HSL in adipocytes through activation of ERK, downstream of the MAPK signaling. Importantly, ERK-mediated activation occurred by phosphorylation on Ser 600 of HSL, which corresponds to the phosphosite targeted by cAMP-activated PKA (126). Instead, TNF $\alpha$ was not reported to induce any change in expression levels of HSL. Similarly, to TNF $\alpha$, ZAG was demonstrated to cause hyperactivation of HSL by leading to increases in cAMP levels and subsequent activation of adenylyl cyclase in a dose dependent manner $(93,127)$. Moreover, differently from TNF $\alpha, Z A G$ was reported to induce upregulation of expression of Gas (a G-protein subunit involved in activation of adenylate cyclase pathway) and HSL, and downregulation of expression of Gai (a G-protein subunit involved in inhibition of adenylate cyclase pathway) (128). Interestingly, some experimental data suggested that ZAG expression in adipocytes might be negatively regulated by TNF $\alpha$ (92).

Further evidence about involvement of procachectic cytokines in fat loss during cachexia was found for IL-6. High levels of this cytokine in the plasma of cachectic mice correlated with enhanced AT lipolysis and increased levels of circulating free fatty acids. These changes were shown to be associated with activation of IL-6 signaling in WAT, which caused downstream activation of STAT3 and p38 $(11,129)$. All the above mentioned pathways are represented in Figure 2.

\section{Enhanced Thermogenesis During CC}

As outlined above, most of cachectic cancer patients experience involuntary excessive energy expenditure. A considerable fraction of this phenomenon has been attributed to aberrant activation of thermogenesis, which, in general, involves the interplay of two main actors, i.e., SM and the brown adipose tissue (BAT) (130). In both cases, this event seems to depend on expression of high amounts of uncoupling proteins (UCPs). UCPs are located on the inner membrane of mitochondria and redirect them toward heat generation instead of ATP synthesis (130). In particular, UCP1 seems to be prevalent in BAT, while UCP2 and UCP3 would be primarily expressed in SM $(131,132)$.

Browning of white adipocytes is the process by which adipocytes of the WAT are transformed into beige adipocites, consequently to endocrine, paracrine, or autocrine stimulation. This phenotypic transition seems to occur during the initial stages of CC, preceding SM atrophy (133). Several reports have argued that WAT browning mainly relies on increased expression of UCP1 in mitochondria of white adipocytes [e.g., (134)]. Nonetheless, some recent studies have remarked the nonconsistency of these results for certain models of experimental cachexia and questioned the real importance of UCP1 in such a context. A possible key role was suggested for the transcriptional coactivator cell death inducing DFFA-like effector A (CIDEA), which is highly expressed in WAT and has a role in lipid metabolism (2). However, this topic has remained controversial.

Both PTHrP and IL-6 were reported to drive the expression of thermogenic genes in vivo, including UCP1, CIDEA, and PGC1 $\alpha(10,90)$. Consistent with this, neutralization of PTHrP or IL- 6 in cachectic mice prevented WAT browning, rescued the cachectic phenotype and blocked the increased expression of UCP1 in subcutaneous AT of C26-bearing mice $(10,11)$. Moreover, silencing of IL- 6 reversed the enhanced mitochondrial respiration in WAT of tumor-bearing mice toward the normal condition (11). However, it remained to understand whether these two factors induced thermogenesis by direct or indirect action on WAT/BAT.

Concerning PTHrP, the evidence that knockout of PTHR in AT blocked adipose browning and wasting provided a strong validation of direct action of PTHrP on both WAT and BAT (90). Surprisingly, the same study demonstrated that knockdown of PTHR in AT also prevented lean mass depletion and improved muscle strength. This raised the question whether PTHrP exerts a direct action even toward SM or not. Indeed, besides the well-known cross-talk between AT and SM (2, 135), a direct effect of PTHrP on myocytes could be also speculated. In fact, a previous report demonstrated that PTH1R expression is required for myocyte differentiation and is highly expressed by CD34or PAX7-positive myosatellite cells in both mice and humans (136). In the same study, it was shown that myotubes also express PTH1R, albeit to a much lesser extent than differentiating myoblasts (136).

Regarding the role of IL-6 in WAT browning, elegant experiments carried on an in vitro model of pre-brown adipocytes demonstrated a direct, though modest, effect of IL-6 on UCP1 expression (11). Nonetheless, mechanistic 


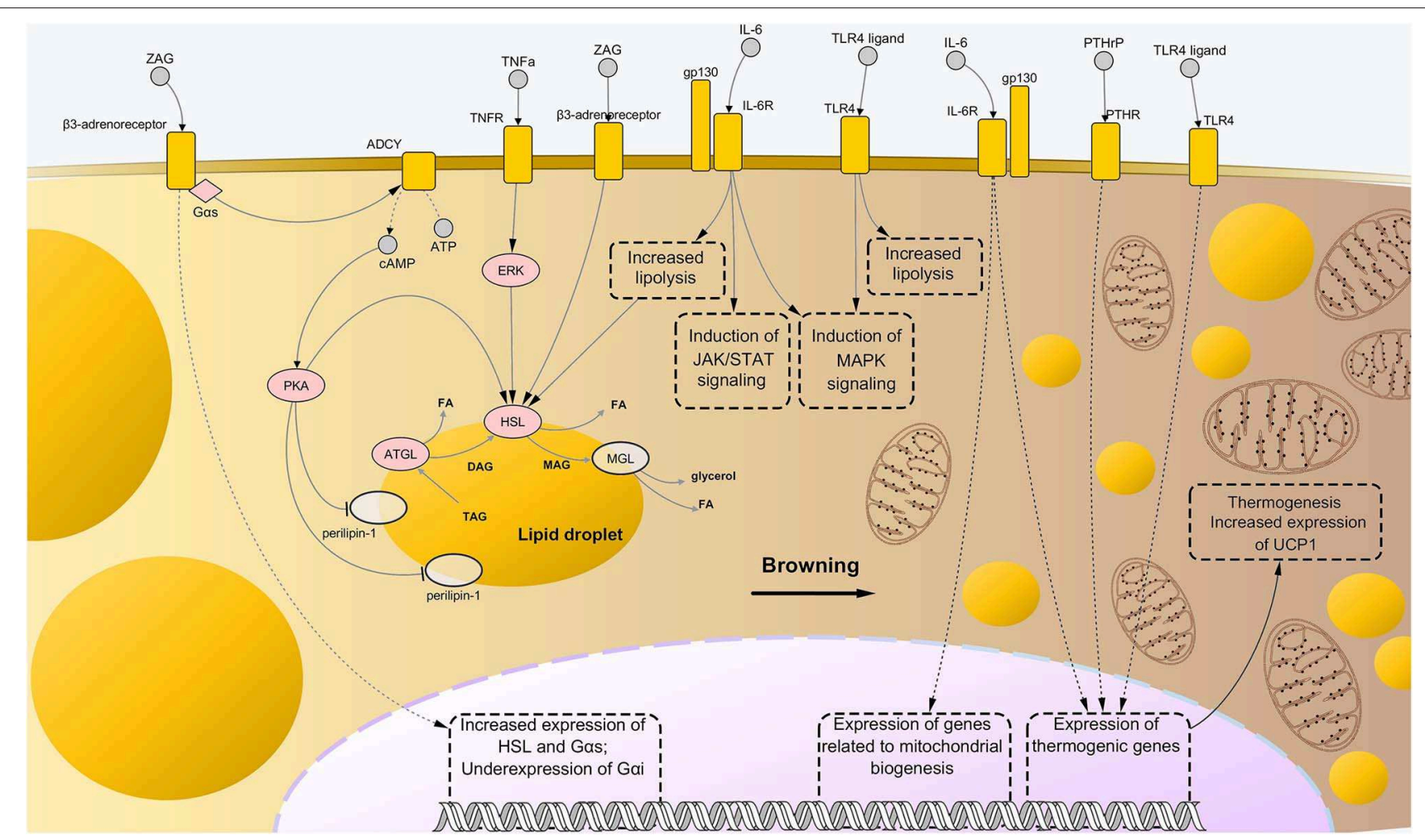

FIGURE 2 | Molecular mechanisms driving adipose tissue loss and remodeling during cancer cachexia. Similarly to the case of skeletal muscle wasting, the combination of abnormally activated pathways including $\beta$-adrenergic signaling, cytokine- and toll-like receptor (TLR)-mediated inflammation, and parathyroid-related peptide (PTHrP) stimulation, leads to enhanced lipolysis and thermogenesis of the AT in cancer cachexia. In particular, binding of interleukin-6 (IL-6) and tumor necrosis factor alpha (TNF $\alpha$ ) to their respective membrane receptors induce high phosphorylation levels of enzymes involved in catabolism of triglycerides, i.e., adipose triglyceride lipase (ATGL) and hormone-sensitive lipase (HSL), implying higher rates of their enzyme activity. Interaction between zinc- $\alpha 2$-glycoprotein (ZAG) and beta-3 adrenergic receptor is known to induce even stronger lipolytic effects than those mediated by IL-6 and TNF $\alpha$, partly due to induction of expression of lipolytic genes (including $G$ proteins of the type $\mathrm{G} \alpha \mathrm{s}$ ) and suppression of expression of $\mathrm{G} \alpha \mathrm{s}$, an inhibitor of $\beta$-adrenergic signaling. Moreover, ZAG promotes phosphorylation of perilipin-1, which results in wider exposition of lipid droplets to the catabolic action of ATGL, HSL, and monoglyceride lipase (MGL). A role in enhanced lipolysis during cancer cachexia has been demonstrated also for TLR4, although precise mechanisms remained largely elusive. Meanwhile, such pattern recognition receptor seems to exert an important role during cachexia-driven white adipose tissue browning, along with IL-6 and PTHrP, promoting expression of thermogenic genes, such as uncoupling protein 1 (UCP1), and favoring mitochondrial biogenesis. In the present illustration, the process of browning proceeds from the left to the right side of the figure, with the left side presenting bigger lipid droplets and almost mitochondria, while the right side presenting a large number of small, sparse lipid droplets and mitochondria. Upregulated nodes are colored in pink and connected with other nodes through continuous edges. Non-deregulated nodes are represented as semi-transparent nodes. Dashed edges represent connections between transcriptional/co-transcriptional factors and gene expression. ADCY, adenylate cyclases; ATP, adenosine triphosphate; cAMP, cyclic adenosine monophosphate; DAG, diglyceride; FA, fatty acid; gp130, glycoprotein-130 IL-6R, IL-6 receptor; JAK, Janus kinase; MAG, monoglyceride; MAPK, mitogen-activated protein kinase; PTHR, parathyroid receptor; STAT, signal transducer and activator of transcription; TAG, triglyceride; TNFR, tumor necrosis factor receptor.

insights regarding this aspect remained elusive. Indeed, IL6 was suggested to mediate thermogenic effects on BAT through activation of $\mathrm{p} 38$, which is known to induce increased mitochondrial biogenesis and expression of thermogenic genes (137, 138). Another possible mechanism would involve the IL-6-mediated activation of AMP-activated protein kinase (AMPK), which in turn would cause an increase in hydrolase activity of ATGL and inactivation of mTORC1 (129). However, the dominant idea is that IL-6-mediated enhancement of thermogenesis and lipolysis is the outcome of both direct and indirect actions of this cytokine on BAT and WAT (139-142).

A role in increased lipolysis and WAT browning was recently demonstrated for TLR4 as well (74). Precisely, LLC-bearing mice showed enhanced lipogenic activity and AT remodeling, while cachectic mice knockout for TLR4 showed reduced thermogenic activity BAT, underexpression of UCP1, and lower phosphorylation levels of p38 compared to the former group (74). This may suggest a potential connection between TLR4, MAPK signaling (70) and transcription of UCP1. Pathways related to WAT browning are represented in Figure 2.

\section{Discrepancies: From the Laboratory to the Clinical Practice}

In spite of the considerable knowledge we have lastly gained regarding CC, the clinical practice still lacks standard diagnostic criteria and treatment guidelines. One of the main reason for such difficulties certainly reside in the multifactorial nature of this syndrome, and thus in its intrinsic complexity. On the other 
hand, however, the scarceness of experimental models of CC capable to accurately recapitulate the features of human CC in various tumor types has represented a major limitation in relation to this issue.

Most preclinical studies conducted so far have been mainly based on exploitation of few ascertained animal models of cachexia-inducing tumors, including LLC, C26 and Yoshida ascites hepatoma (YAH 130) (143). These were chosen and maintained as general models of CC owing to the broad documentation in their regard. However, a lot of skepticism have been lastly raised about their actual potential to be employed as reliable surrogates of human CC. In particular, it is now becoming predominant the opinion that the failure of most anticachexia therapeutics to reach primary endpoints during clinical trials (see the next section) is at least in part attributable to the limitations imposed by the use of inappropriate experimental models (143). In line with this reasoning, a number of recent studies have demonstrated the relative inconsistency of such models, since their molecular characterization at the tissue level revealed quite different patterns of gene expression between animal models and human patients [e.g., $(144,145)]$.

In this context, genetically engineered mouse (GEM) models of CC are being evaluated as a relevant solution to overcome such restrictions. GEM models currently tested for preclinical studies avail of the tamoxifen-inducible conditional genetic mutation system Cre-ER (146). Adenovirus-containing Cre-ER encodes for a fusion protein in which a mutated hormone-binding domain of the estrogen receptor $\left(\mathrm{ER}^{\mathrm{T}}\right.$ or $\left.\mathrm{ER}^{\mathrm{T} 2}\right)$ is fused to Cre, a bacterial site-specific recombinases that catalyzes recombination between well-defined "loxP" sites flanking the gene of interest (146-148). As this system relies upon the presence of tamoxifeninducible promoters, it allows the spatio-temporal control of Cre expression, with the subsequent deletion of genes flanked by loxP sites. In contrast with tumors developed by traditional CC models, tumors arising in GEM models closely mimic the histopathological and molecular features of their human counterparts and spontaneously progress toward metastases and cachexia.

A valuable GEM model of CC is that engineered by Talbert et al. (144), which was proved to closely resemble the typical features reported for cachexia induced by pancreatic ductal adenocarcinoma (PDA) in human patients. The mouse model, named KPP (Kras ${ }^{+/ G 12 D}, P_{t f 1 a}^{+/ E R-C r e}, \operatorname{Pten}^{\mathrm{f} / \mathrm{f}}$ ), exhibited progressive wasting of SM, heart and AT mass, similar to that experienced by humans, and gene ontology of its SM-derived mRNAs resembled that of PDA patients (144). By contrast, this model displayed loss of normal pancreatic parenchyma, which could significantly contribute to weight loss in KPP mice. Furthermore, it is likely that such a model is selective for PDA, and thus not suitable for studying cachexia associated to other tumor types (144). In the same study, the GEM model KPC $\left(\mathrm{Kras}^{+/ \mathrm{LSL}-\mathrm{G} 12 \mathrm{D}}, \operatorname{Trp} 53^{+/ \mathrm{R} 270 \mathrm{H}}, \mathrm{Pdx} 1^{+/ \mathrm{Cre}}\right)$ was reevaluated. Indeed, KPC is a GEM model of PDA (149) that has been recently considered a reliable model of cachexia by a number of studies [e.g., (11, 150, 151)]. Nonetheless, Talbert et al. demonstrated that changes in size and tissue mass of KPC mice did not correlate with PDA progression, and that patterns of gene expression in their SM did not resemble that of PDA patients (144). Thus, the KPP genotype appears to be more robust for research on CC compared with the KPC model. Further examples of potentially useful GEM for research on CC are the KL model $\left(\mathrm{KRAS}^{\mathrm{G} 12 \mathrm{D} /+} ; \mathrm{LKB1}^{\mathrm{f} / \mathrm{f}}\right)$, recently used to study the metabolic profile of advanced non-small cell lung cancer (NSCLC) (152), and the lately developed KPC:APC model $\left(\mathrm{APC}^{\mathrm{f} / \mathrm{f}}\right.$; $\mathrm{KRAS}^{+/ \mathrm{f}}$; CDX2-Cre-ER ${ }^{\mathrm{T} 2}$ ), which aims to recapitulate features of human colorectal carcinoma (CRC) with mutated KRAS and leads to development of CC (153).

Orthotopic models of patient-derived cancer cells (PDCC) may represent another valuable option for research on CC. Here, tumor cells derived from human patients are seeded into the corresponding tissue of immunocompromised animal models. This has the obvious advantage of allowing the study of organ-specific tumor microenvironment with increased accuracy and higher genetic heterogeneity and stability compared to the traditional xenograft models, similarly to GEM models. In particular, this was demonstrated for both orthotopic and subcutaneous engraftment of patient-derived pancreatic tumor $(154,155)$. However, some data suggested that orthotopic engraftment of pancreatic tumor cells within mice's pancreas could induce systemic inflammation distinct from that observed in subcutaneous engraftments, leading toward more severe SM wasting [e.g., (154)].

One limitation of orthotopic models of CC is that here engrafted PDCC maintains their metastatic potential (154, 156), thus preventing researchers to study stages related to development and progression of cachexia. Moreover, lean mass loss in these models may be the result of postsurgical inflammation instead of tumor-induced tissue loss. Yet, the exploitation of immunocompromised mice for generating orthotopic models may fail in reproducing the immune profile of CC (144). The latter limitation, however, can be overcome by employing syngeneic mouse models of GEM-derived tumors, i.e., models in which immune-competent mice are implanted with tumor cells derived from GEM presenting the same genetic background [e.g., (157)].

\section{CURRENT UNIMODAL TREATMENT OPTIONS FOR CC}

There is a wide range of treatment options currently available for CC. Nutritional support is very important in cancer patients, as their food intake is often reduced due to symptoms like anorexia caused by systemic inflammation, nausea, vomiting, and mucositis (158). For these reasons, as soon as patients are diagnosed with cancer, they should be nutritionally monitored and receive both nutritional and metabolic support (159). Meanwhile, since systemic inflammation is a hallmark of CC, the pharmacological targeting of individual proinflammatory cytokines or that of their cognate receptors has been considered as a potential powerful approach. Also, several hormones and hormone-derived compounds known to stimulate appetite and to induce weight gain have been tested. Nonetheless, most of the current trialed agents has not received the FDA (Food and Drug 
Administration) approval since either no substantial benefits or manifestation of important side effects were observed throughout Phase I/III of clinical trials $(143,160)$ (Table 1).

\section{TNF $\alpha$, IL-6, and IL-1 Inhibitors}

Because of their widely recognized role in induction of cachectigenic effects, TNF $\alpha$, IL-6, and IL- $1 \alpha$ had represented the ideal target of several anti-cachectic compounds. However, in the case of anti-TNF $\alpha$ therapy, neither the $\mathrm{TNF} \alpha$ receptor-blocker Etanercept (161) nor the chimeric IgG1 kappa monoclonal antibody Infliximab (167) were able to prevent muscle atrophy or improve appetite in two randomized controlled trials of terminal cachectic patients. Moreover, Infliximab was found to increase fatigue and treatment-related mortality in administrated patients (167). Likewise, slight recovery of muscle mass accompanied by worsening of life or no significant beneficial effects were reported by five randomized clinical trials testing two pharmacological agents capable to downregulate expression of TNF $\alpha$, namely Thalidomide (162-164) and Pentoxifylline (165, 166), respectively.

Anti-IL-6 and anti-IL-1 $\alpha$ pharmacological agents showed promising results over the course of clinical trials; nonetheless, they were inconclusive in terms of clinical management of the disease. Specifically, in a Phase I clinical trial involving patients with advanced cancer, the humanized anti-IL-6 monoclonal antibody Clazakizumab was well tolerated, increased hemoglobin and albumin levels and reversed fatigue in treated patients (168). During the subsequent Phase II randomized controlled trial, administration of Clazakizumab to patients with NSCLC resulted in a slight lower degree of lean mass depletion (169). However, effects on SM mass were not considered satisfactory according to the acceptance criteria and further studies were required (188). Similarly, in Phase I and III clinical trials, the IL- $1 \alpha$-specific humanized monoclonal antibody Xilonix was found to prevent alteration of body composition and improve control of thrombocytosis in refractory cancer patients (171) and advanced CRC patients with cachexia (172), respectively. The most common adverse events observed at the end of these studies were proteinuria (171), anemia and increased concentration of both alkaline phosphatase and aspartate aminotransferase (172). A second phase III clinical trial attempting to further demonstrate the efficacy of Xilonix in advanced CRC patients (NCT01767857) was stopped at its early stage as the study crossed the prospective futility boundary of primary endpoint.

Indirect blockage of IL- 6 action by pharmacological inhibition of the JAK/STAT3 signaling may represent another valid strategy to be persued. In preclinical studies, the allosteric inhibitor of MAPK/ERK kinase 1 (MEK1) and 2 (MEK2) Selumetinib was proved to exert tumor suppressive activity and prevent cancerinduced IL-6 production [e.g., (189)]. Yet, results from a Phase II trial conducted in patients with metastatic biliary cancers suggested that Selumetinib induced non-fluid weight gain in administrated patients (170). Thus, this drug was tested in a Phase II trial in patients with advanced cholangiocarcinoma, aiming to study its potential as modulator of IL-6/JAK/STAT3 signaling and mediator of SM anabolism (22). Despite results showed that Selumetinib effectively promoted SM gain in patients with cholangiocarcinoma, its actual relevance for $\mathrm{CC}$ remained to be demonstrated (22).

Similarly, the selective JAK1/2 inhibitor Ruxolitinib was trialed on patients with myelofibrosis and was found to reduce splenomegaly and disease-related symptoms, meanwhile inducing a significant increase in body weight (190). An openlabel Phase II trial was then started in 2014 aiming to examine both safety and efficacy of Ruxolitinib as well as its influence on overall survival. However, enrollment of participants for this study did not succeed and the trial was unsuccessfully terminated at the beginning of 2019 due to poor recruiting (NCT02072057).

\section{Non-steroidal Anti-inflammatory Drugs}

Non-steroidal anti-inflammatory drugs (NSAID) have been considered to counteract chronic inflammation in CC as well. In particular, Celecoxib, a cyclooxygenase-2 (COX-2) inhibitor, significantly improved QoL and BMI in cachectic patients vs. control (173). Another study reported significant increases of lean mass and improvements in handgrip strength and QoL in patients with advanced cancers administrated with Celecoxib (174). In addition, a significant decrease in TNF $\alpha$ levels was observed, and no particular toxic effects were reported (174). More recently, several trials have evaluated the effects of a combination of Celecoxib with other drugs on cachectic patients, including combination with L-carnitine [a nutritional supplement that improves the cachectic condition (191)] and combination of these two compounds plus Megestrol acetate (see below). These studies led to more effective improvements in lean mass, total physical activity and decreased sense of fatigue, without toxic effects (192).

\section{Myostatin Inhibitors}

In recent times, the treatment of cachexia has been focused on myokines, which include cytokines and other proteins produced and secreted by SM cells $(193,194)$. Among these, Mstn can act as autocrine, paracrine or endocrine effector along with cytokines like IL-6, IL-8, and IL-15, and is responsible for immune and metabolic changes associated to exercise or stress (193-195). Thus, Mstn inhibitors have been considered promising tools for the treatment of cachexia. In 2012, two Phase I clinical trials under the same study evaluated the safety and tolerability of the humanized monoclonal antibody to myostatin LY2495655 in healthy subjects and patients with advanced cancer (175). According to the results obtained, the efficacy of LY2495655 was well demonstrated in the case of healthy volunteers, in which it caused an increase in thigh muscle volume. Increases in muscle volume were observed also in patients with advanced cancer, though only when the drug was administrated at relatively low doses (21 and 70-mg) without unusual safety concerns (175). In 2018, a Phase II trial was performed on a group of inoperable patients or with metastatic pancreatic cancer, who suffered from cachexia. Here, patients were treated with different doses of LY2495655, and the authors reported that pre-cachectic patients were more responsive to the treatment than cachectic patients (176). These results may suggest that treatment with LY2495655 should be better considered for prevention muscle loss rather 
TABLE 1 | Table summarizing unimodal treatment options mentioned in this review.

\begin{tabular}{|c|c|c|c|c|c|c|c|}
\hline Drug name & Drug class & Molecule type & Disease & Status & Positive outcomes & $\begin{array}{l}\text { Adverse effects/ } \\
\text { Difficulties }\end{array}$ & References \\
\hline Etanercept & $\begin{array}{l}\text { Anti-TNF } \alpha \\
\text { therapy }\end{array}$ & TNF $\alpha$ receptor-blocker & $\begin{array}{l}\text { Cancer (other than } \\
\text { brain cancer) }\end{array}$ & $\begin{array}{l}\text { Phase III RCT } \\
\text { (placebo) }\end{array}$ & - & $\begin{array}{l}\text { Induced negligible weight } \\
\text { gain; did not improve median } \\
\text { survival; caused higher rates } \\
\text { of neurotoxicity. }\end{array}$ & $\begin{array}{l}\text { NCT00046904 } \\
\text { (161) }\end{array}$ \\
\hline Thalidomide & $\begin{array}{l}\text { Anti-TNF } \alpha \\
\text { therapy }\end{array}$ & $\begin{array}{l}\text { Synthetic derivative of } \\
\text { glutamic acid }\end{array}$ & Pancreatic cancer & RCT (placebo) & $\begin{array}{l}\text { Attenuated weight and } \\
\text { lean body mass losses }\end{array}$ & $\begin{array}{l}\text { No significant improvements } \\
\text { of QoL }\end{array}$ & $(162)$ \\
\hline Thalidomide & $\begin{array}{l}\text { Anti-TNF } \alpha \\
\text { therapy }\end{array}$ & $\begin{array}{l}\text { Synthetic derivative of } \\
\text { glutamic acid }\end{array}$ & Cancer & Phase III RCT & $\begin{array}{l}\text { Significant decrease in } \\
\text { levels of circulating IL-6; } \\
\text { did not cause } \\
\text { worsening of life }\end{array}$ & $\begin{array}{l}\text { Lack of satisfactory } \\
\text { documentation }\end{array}$ & $(163)$ \\
\hline Thalidomide & $\begin{array}{l}\text { Anti-TNF } \alpha \\
\text { therapy }\end{array}$ & $\begin{array}{l}\text { Synthetic derivative of } \\
\text { glutamic acid }\end{array}$ & Cancer & RCT (placebo) & $\begin{array}{l}\text { Slight decrease in levels } \\
\text { of circulating IL- } 6 \text { and } \\
\text { TNF } \alpha\end{array}$ & $\begin{array}{l}\text { No significant benefits } \\
\text { compared with placebo; } \\
\text { possible risk of } \\
\text { treatment-related mortality }\end{array}$ & $(164)$ \\
\hline Pentoxifylline & $\begin{array}{l}\text { Anti-TNF } \alpha \\
\text { therapy }\end{array}$ & Methylxanthine derivative & $\begin{array}{l}\text { Cancer (other than } \\
\text { brain cancer) }\end{array}$ & RCT (placebo) & - & $\begin{array}{l}\text { No differences in QoL and } \\
\text { possible worsening of life } \\
\text { after } 4 \text { weeks of treatment }\end{array}$ & $(165)$ \\
\hline Pentoxifylline & $\begin{array}{l}\text { Anti-TNF } \alpha \\
\text { therapy }\end{array}$ & Methylxanthine derivative & Cancer & RCT (placebo) & No toxicity & $\begin{array}{l}\text { Did not improve appetite nor } \\
\text { significant weight gain }\end{array}$ & $(166)$ \\
\hline Infliximab & $\begin{array}{l}\text { Anti-TNF } \alpha \\
\text { therapy }\end{array}$ & $\begin{array}{l}\text { Chimeric lgG1k monoclonal } \\
\text { antibody }\end{array}$ & NSCLC & $\begin{array}{l}\text { Phase III RCT } \\
\text { (placebo)/ } \\
\text { docetaxel }\end{array}$ & - & $\begin{array}{l}\text { Did not induced weight } \\
\text { gaining; caused increased } \\
\text { fatigue and inferior global } \\
\text { QoL }\end{array}$ & $\begin{array}{c}\text { NCT00040885 } \\
(167)\end{array}$ \\
\hline Clazakizumab & $\begin{array}{l}\text { Anti-IL6 } \\
\text { therapy }\end{array}$ & $\begin{array}{l}\text { Humanized anti-IL-6 } \\
\text { monoclonal antibody }\end{array}$ & Cancer & Phase I CT & $\begin{array}{l}\text { No apparent toxicity; } \\
\text { increased hemoglobin } \\
\text { and albumin levels; } \\
\text { reduced fatigue }\end{array}$ & $\begin{array}{l}\text { Lack of satisfactory } \\
\text { documentation }\end{array}$ & $(168)$ \\
\hline Clazakizumab & $\begin{array}{l}\text { Anti-IL6 } \\
\text { therapy }\end{array}$ & $\begin{array}{l}\text { Humanized anti-IL-6 } \\
\text { monoclonal antibody }\end{array}$ & NSCLC & Phase II RCT & $\begin{array}{l}\text { Generally well tolerated; } \\
\text { improved the lung } \\
\text { symptom score; } \\
\text { attenuated lean mass } \\
\text { loss; reversed fatigue }\end{array}$ & $\begin{array}{l}\text { May cause rectal } \\
\text { hemorrhage or } \\
\text { treatment-related mortality in } \\
\text { a minority of patients; } \\
\text { inconclusive in terms of } \\
\text { clinical management }\end{array}$ & $\begin{array}{c}\text { NCT00866970 } \\
(169)\end{array}$ \\
\hline Selumetinib & $\begin{array}{l}\text { Anti-IL6 } \\
\text { therapy }\end{array}$ & MEK1/2 inhibitor & Biliary cancer & Phase II CT & $\begin{array}{l}\text { Overall acceptable } \\
\text { tolerability; induced } \\
\text { significant weight } \\
\text { gaining }\end{array}$ & $\begin{array}{l}\text { Induced low-grade adverse } \\
\text { events including rush and } \\
\text { xerostomia; may worsen } \\
\text { fatigue in a minority of } \\
\text { patients }\end{array}$ & $\begin{array}{c}\text { NCT00553332 } \\
(170)\end{array}$ \\
\hline Selumetinib & $\begin{array}{l}\text { Anti-IL6 } \\
\text { therapy }\end{array}$ & MEK1/2 inhibitor & Cholangiocarcinoma & Phase II CT & $\begin{array}{l}\text { Induced significant } \\
\text { gaining of lean body } \\
\text { mass }\end{array}$ & $\begin{array}{l}\text { Lack of satisfactory } \\
\text { documentation }\end{array}$ & (22) \\
\hline Ruxolitinib & $\begin{array}{l}\text { Anti-IL6 } \\
\text { therapy }\end{array}$ & JAK1/2 inhibitor & Cancer & Phase II CT & - & $\begin{array}{l}\text { The study was terminated } \\
\text { due to poor recruiting }\end{array}$ & NCT02072057 \\
\hline Xilonix & $\begin{array}{l}\text { Anti-IL-1 } \alpha \\
\text { therapy }\end{array}$ & $\begin{array}{l}\text { IL-1 } \alpha \text {-specific humanized } \\
\text { monoclonal antibody }\end{array}$ & Cancer & Phase I CT & $\begin{array}{l}\text { Well tolerated by all } \\
\text { participants, no } \\
\text { dose-limiting toxicities } \\
\text { were reported }\end{array}$ & $\begin{array}{l}\text { Caused proteinuria, anemia, } \\
\text { nausea and fatigue in a } \\
\text { minor fraction of patients }\end{array}$ & $\begin{array}{c}\text { NCT01021072 } \\
(171)\end{array}$ \\
\hline Xilonix & $\begin{array}{l}\text { Anti-IL-1 } \alpha \\
\text { therapy }\end{array}$ & $\begin{array}{l}\text { IL-1 } \alpha \text {-specific humanized } \\
\text { monoclonal antibody }\end{array}$ & $\mathrm{CRC}$ & $\begin{array}{l}\text { Phase III RCT } \\
\text { (placebo) }\end{array}$ & $\begin{array}{l}\text { Prevented alteration of } \\
\text { body composition and } \\
\text { improved control of } \\
\text { thrombocytosis }\end{array}$ & $\begin{array}{l}\text { Caused proteinuria, anemia, } \\
\text { increased concentration of } \\
\text { alkaline phosphatase and } \\
\text { aspartate aminotransferase } \\
\text { and fatigue in a minor } \\
\text { fraction of patients }\end{array}$ & $\begin{array}{c}\text { NCT01767857 } \\
(172)\end{array}$ \\
\hline Xilonix & $\begin{array}{l}\text { Anti-IL-1 } \alpha \\
\text { therapy }\end{array}$ & $\begin{array}{l}\text { IL-1 } \alpha \text {-specific humanized } \\
\text { monoclonal antibody }\end{array}$ & $\mathrm{CRC}$ & Phase III CT & - & $\begin{array}{l}\text { The study was stopped as it } \\
\text { crossed the prospective } \\
\text { futility boundary of primary } \\
\text { endpoint }\end{array}$ & NCT01767857 \\
\hline Celecoxib & NSAID & $\begin{array}{l}\text { Cyclooxygenase-2 (COX-2) } \\
\text { inhibitor }\end{array}$ & Cancer & $\begin{array}{l}\text { Phase II RCT } \\
\text { (placebo) }\end{array}$ & $\begin{array}{l}\text { Significantly improved } \\
\text { BMI and QoL; moderate } \\
\text { decrease of IL- } 6 \text { levels } \\
\text { after } 3 \text { weeks of } \\
\text { treatment }\end{array}$ & - & $(173)$ \\
\hline
\end{tabular}


TABLE 1 | Continued

\begin{tabular}{|c|c|c|c|c|c|c|c|}
\hline Drug name & Drug class & Molecule type & Disease & Status & Positive outcomes & $\begin{array}{l}\text { Adverse effects/ } \\
\text { Difficulties }\end{array}$ & References \\
\hline Celecoxib & NSAID & $\begin{array}{l}\text { Cyclooxygenase-2 (COX-2) } \\
\text { inhibitor }\end{array}$ & Cancer & Phase II CT & $\begin{array}{l}\text { Significantly improved } \\
\text { BMI and QoL; moderate } \\
\text { decrease of TNF } \alpha \\
\text { levels; increased } \\
\text { handgrip strength and } \\
\text { improved performance } \\
\text { status }\end{array}$ & - & (174) \\
\hline Bimagrumab & $\begin{array}{l}\text { Mstn } \\
\text { inhibition }\end{array}$ & $\begin{array}{l}\text { Human monoclonal } \\
\text { anti-ActRII antibody }\end{array}$ & $\begin{array}{l}\text { NSCLC and } \\
\text { Pancreatic } \\
\text { adenocarcinoma }\end{array}$ & $\begin{array}{l}\text { Phase II RCT } \\
\text { (placebo) }\end{array}$ & $\begin{array}{l}\text { Significant increase in } \\
\text { lean body mass and } \\
\text { thigh muscle volume }\end{array}$ & $\begin{array}{l}\text { Significant decrease in total } \\
\text { body weight }\end{array}$ & NCT01433263 \\
\hline AMG 745 & $\begin{array}{l}\text { Mstn } \\
\text { inhibition }\end{array}$ & Fc fusion peptibody & Prostate cancer & $\begin{array}{l}\text { Phase I RCT } \\
\text { (placebo) }\end{array}$ & $\begin{array}{l}\text { Generally well tolerated; } \\
\text { increased lean body } \\
\text { mass }\end{array}$ & $\begin{array}{l}\text { Slight decrease in fat mass; } \\
\text { may cause adverse events } \\
\text { including diarrhea and fatigue }\end{array}$ & $\begin{array}{c}\text { NCT00975104 } \\
\text { (177) }\end{array}$ \\
\hline $\begin{array}{l}\text { Megestrol } \\
\text { acetate (FDA } \\
\text { approved) }\end{array}$ & $\begin{array}{l}\text { Appetite } \\
\text { stimulant }\end{array}$ & Progesteron derivative & Several cancer types & Summary of $35 \mathrm{CT}$ & $\begin{array}{l}\text { Improvement of } \\
\text { appetite and increased } \\
\text { caloric intake, weight } \\
\text { gain and nutritional } \\
\text { status; improvement of } \\
\text { QoL; downregulation of } \\
\text { proinflammatory } \\
\text { cytokines or that of their } \\
\text { cognate receptors }\end{array}$ & $\begin{array}{l}\text { More than } 40 \text { side effects } \\
\text { including edema, } \\
\text { thromboembolitic episodes } \\
\text { and treatment-related death }\end{array}$ & $\begin{array}{l}\text { Summary of } 35 \\
\text { clinical trials } \\
\text { (178) }\end{array}$ \\
\hline Ghrelin & $\begin{array}{l}\text { Orexigenic } \\
\text { mediator }\end{array}$ & Hormone & Esophageal cancer & $\begin{array}{l}\text { Phase II RCT } \\
\text { (placebo) + } \\
\text { cisplatin-based } \\
\text { neoadjuvant } \\
\text { chemotherapy }\end{array}$ & $\begin{array}{l}\text { Increased food } \\
\text { consumption and } \\
\text { weight gain; reduced } \\
\text { nausea and anorexia } \\
\text { related to chemotherapy }\end{array}$ & - & (180) \\
\hline $\begin{array}{l}\text { Anamorelin } \\
\mathrm{HCl}\end{array}$ & $\begin{array}{l}\text { Orexigenic } \\
\text { mediator }\end{array}$ & Ghrelin Receptor agonist & NSCLC & Phase III & $\begin{array}{l}\text { Generally well tolerated; } \\
\text { improved appetite; } \\
\text { increased food intake, } \\
\text { body weight and lean } \\
\text { body mass }\end{array}$ & $\begin{array}{l}\text { Caused hyperglycemia, } \\
\text { nausea and gastrointestinal } \\
\text { disorders in a minority of } \\
\text { patients; no significant } \\
\text { improvement of handgrip } \\
\text { strength }\end{array}$ & $\begin{array}{c}\text { NCT01387269 } \\
(181)\end{array}$ \\
\hline $\begin{array}{l}\text { Anamorelin } \\
\mathrm{HCl}\end{array}$ & $\begin{array}{l}\text { Orexigenic } \\
\text { mediator }\end{array}$ & Ghrelin Receptor agonist & NSCLC & Phase III & $\begin{array}{l}\text { Generally well tolerated; } \\
\text { improved appetite; } \\
\text { increased food intake, } \\
\text { body weight and lean } \\
\text { body mass }\end{array}$ & $\begin{array}{l}\text { Caused hyperglycemia, } \\
\text { nausea and gastrointestinal } \\
\text { disorders in a minority of } \\
\text { patients; no significant } \\
\text { improvement of handgrip } \\
\text { strength }\end{array}$ & $\begin{array}{c}\text { NCT01387282 } \\
\text { (181) }\end{array}$ \\
\hline
\end{tabular}


TABLE 1 | Continued

\begin{tabular}{|c|c|c|c|c|c|c|c|}
\hline Drug name & Drug class & Molecule type & Disease & Status & Positive outcomes & $\begin{array}{l}\text { Adverse effects/ } \\
\text { Difficulties }\end{array}$ & References \\
\hline $\begin{array}{l}\text { Anamorelin } \\
\mathrm{HCl}\end{array}$ & $\begin{array}{l}\text { Orexigenic } \\
\text { mediator }\end{array}$ & Ghrelin Receptor agonist & NSCLC & Phase III & $\begin{array}{l}\text { Generally well tolerated; } \\
\text { improved appetite; } \\
\text { increased food intake, } \\
\text { body weight and lean } \\
\text { body mass }\end{array}$ & $\begin{array}{l}\text { Caused hyperglycemia, } \\
\text { nausea and gastrointestinal } \\
\text { disorders in a minority of } \\
\text { patients; no significant } \\
\text { improvement of handgrip } \\
\text { strength }\end{array}$ & $\begin{array}{c}\text { NCT01395914 } \\
(182)\end{array}$ \\
\hline THC & $\begin{array}{l}\text { Appetite } \\
\text { stimulant } \\
\text { and } \\
\text { metabolism } \\
\text { modulator }\end{array}$ & $\begin{array}{l}\text { Endogenous agonist of CB1 } \\
\text { and } \mathrm{CB} 2 \text { receptors }\end{array}$ & Cancer & Phase III CT & $\begin{array}{l}\text { Well tolerated, no } \\
\text { adverse effects }\end{array}$ & $\begin{array}{l}\text { No significant improvements } \\
\text { in appetite or QoL }\end{array}$ & $(183)$ \\
\hline THC & $\begin{array}{l}\text { Appetite } \\
\text { stimulant } \\
\text { and } \\
\text { metabolism } \\
\text { modulator }\end{array}$ & $\begin{array}{l}\text { Endogenous agonist of CB1 } \\
\text { and CB2 receptors }\end{array}$ & Cancer & Phase III CT & $\begin{array}{l}\text { Well tolerated, no } \\
\text { adverse effects; } \\
\text { significant increase in } \\
\text { appetite and caloric } \\
\text { intake; improved } \\
\text { chemosensory } \\
\text { perception and QoL }\end{array}$ & - & $\begin{array}{c}\text { NCT00316563 } \\
(184)\end{array}$ \\
\hline THC & $\begin{array}{l}\text { Appetite } \\
\text { stimulant } \\
\text { and } \\
\text { metabolism } \\
\text { modulator }\end{array}$ & $\begin{array}{l}\text { Endogenous agonist of } \mathrm{CB} 1 \\
\text { and } \mathrm{CB} 2 \text { receptors }\end{array}$ & Cancer & Pilot study & $\begin{array}{l}\text { Well tolerated; } \\
\text { significant increase in } \\
\text { appetite and caloric } \\
\text { intake; improved QoL; } \\
\text { reversed fatigue }\end{array}$ & $\begin{array}{l}\text { May induce dizziness or } \\
\text { anxiety in a small fraction of } \\
\text { patients }\end{array}$ & $\begin{array}{c}\text { NCT02359123 } \\
(185)\end{array}$ \\
\hline Nabilone & $\begin{array}{l}\text { Appetite } \\
\text { stimulant } \\
\text { and } \\
\text { metabolism } \\
\text { modulator }\end{array}$ & Synthetic analog of $\mathrm{THC}$ & NSCLC & $\begin{array}{l}\text { Phase II RCT } \\
\text { (placebo) }\end{array}$ & $\begin{array}{l}\text { Increased appetite and } \\
\text { caloric intake; } \\
\text { improvement of QoL; } \\
\text { attenuated pain and } \\
\text { insomnia }\end{array}$ & - & $\begin{array}{c}\text { NCT02802540 } \\
(186)\end{array}$ \\
\hline Erythropoietin & $\begin{array}{l}\text { Anemia } \\
\text { reversal }\end{array}$ & Hormone & Cancer & Randomized study & $\begin{array}{l}\text { Reversed anemia; } \\
\text { improved exercise ability } \\
\text { and sense of well-being }\end{array}$ & $\begin{array}{l}\text { No significant improvements } \\
\text { in QoL; discrepancies } \\
\text { between objective and } \\
\text { subjective self-reported } \\
\text { measures }\end{array}$ & $(187)$ \\
\hline
\end{tabular}

$C T$, clinical trial; $R C T$, randomized clinical trial.

than for reverting the process, although deeper investigation and additional functional readouts are required.

In 2014, one study described the properties of the human anti-ActRII antibody Bimagrumab (BYM338) (196). BYM338 prevented the binding of ligands to the receptors and hence the activation of signaling pathway downstream of ActRII. In vivo, administration of bimagrumab resulted in significant SM hypertrophy and increased muscle fiber diameter. Furthermore, it protected muscles from glucocorticoid-induced atrophy and weakness through the impairment of muscle and tetanic force losses (196). Lastly, Novartis Pharmaceuticals completed a randomized control trial of BYM338 for treatment of CC associated with pancreatic adenocarcinoma and NSCLC. Patients administrated with Bimagrumab displayed significant increases in lean body mass and thigh muscle volume, yet also had decrement in total body weight (NCT01433263).

Another myostatin inhibitor is AMG 745, a peptibody resulted from the fusion of a human N-terminal Fc region of an immunoglobulin and the $\mathrm{C}$-terminus of a myostatin-neutralizing peptide. AMG 745 has been successfully tested in various murine models including C26 tumor-bearing mice, where it increased SM mass, body weight and strength with respect to the control group (177). In patients undergoing androgen deprivation as a consequence of non-metastatic prostate cancer, AMG 745 was reported to improve the lower-extremity muscle mass (177).

\section{Metabolism and Appetite Modulators}

One of the first pharmacological options proposed for the treatment of CC include Megestrol acetate, an appetite stimulant derived from progesterone capable to improve caloric intake and nutritional status. Albeit its precise mechanism of action still remains undetermined, it has been proven that this hormonederivated drug exerts an anti-inflammatory action, as it has the ability to downregulate proinflammatory cytokines levels or that of their cognate receptors $(197,198)$.

After being tested in several trials, Megestrol acetate was reported to improve cancer patients' appetite, QoL and weight gain compared to placebo group, but not when compared to patients treated with other drugs (178). For this reason, the FDA approved it in 1993 for the treatment of anorexia, cachexia and unexplained weight loss in patients with AIDS (178). Nonetheless, Megestrol acetate was found to be responsible of more than 40 side effects, including odema, thromboembolic episodes and death (178). Yet, a case study about a 65 year-old man who suffered from metastatic renal cell carcinoma revealed that Megestrol acetate can induce adrenal insufficiency (199). 
More recently, the efficacy of the combination of Megestrol acetate plus Thalidomide was tested in cachectic cancer patients compared to the treatment with Megestrol acetate alone (200). At the end of the study, results revealed that the combination of these two drugs was more effective than the treatment with Megestrol acetate alone, as patients showed statistically significant increase in body weight, appetite, QoL and grip strength, as well as significant decrease of IL-6 and TNF $\alpha$ levels (200).

Medroxyprogesterone acetate is another progesterone derivative taken into consideration for the clinical treatment of cancer-related anorexia/cachexia syndrome. At the same extent of Megestrol acecate, Medroxyprogesterone has been shown to impair the synthesis and release of several procachectic cytokines, in particular IL-6, TNF $\alpha$, and IL-1 $(179,197)$. In placebocontrolled studies, it was reported that Medroxyprogesterone generally improved anorexia, QoL and body weight gain, although the latter was caused by an increase in AT rather than lean mass.

Due to his orexigenic properties, ghrelin has been evaluated as palliative remedy in CC. Ghrelin is mainly produced and secreted by the stomach and, to a lesser extent, by other organs such as pancreas, lung, liver, muscle, and AT (201). Ghrelin mediates multiple pathways involved in the regulation of body weight, body composition, energy storage and appetite, and regulates energy expenditure (202). In particular, it has been demonstrated that this hormone causes an increase in food consumption in both rodents and human patients with cancer, leading to significant weight gain [e.g., (180, 202)]. Moreover, patients who received ghrelin manifested less adverse effects during chemotherapy in terms of nausea and anorexia in respect to the control group (180). Thus, ghrelin is considered a potential remedy for the management of CC. However, an apparent contradictory observation was reported by some studies. In fact, cachectic murine models and cancer patients with cachexia both usually presented hyper-ghrelinemia, though paradoxically showing loss of appetite. This is probably due to grelin's short half-life, which is nearly $30 \mathrm{~min}(201,203)$. In order to solve this issue, more stable ghrelin analogs have been developed as potential therapeutic agents. Among them, Anamorelin $\mathrm{HCl}$ has a half-life corresponding to nearly $7 \mathrm{~h}$ and is considered a valid agonist of the ghrelin receptor, as it displays significant appetite-enhancing activity and increases food intake and body weight in rats in a dose-dependent manner (204).

Anamorelin was tested on a group of volunteers in a randomized Phase I clinical trial. At the end of the trial, subjects who underwent the treatment displayed a significant doserelated weight gaining compared to the placebo group, with no particular adverse effects (205). Anamorelin has also been tested in several Phase II trials, with patients suffering from different types of solid and blood tumors, showing safety and efficacy (206). Notoriously, Anamorelin has been widely tested on patients with NSCLC during the ROMANA international clinical trials. ROMANA 1 and ROMANA 2 are two randomized Phase III trials performed on cachectic patients with incurable stage III/IV NSCLC for 12 weeks (181). In both studies, the Functional
Assessment of Anorexia/Cachexia Therapy (FAACT) and the fatigue domain of the Functional Assessment of Chronic Illness Therapy-Fatigue (FACIT-F) showed an improvement in patient conditions, with an increase in body weight compared to the placebo group (181). Across the groups, Anamorelin treatment was well tolerated and caused general improvement of anorexiacachexia symptoms, with the exception of some low incidence adverse events such as grade 1-2 hyperglycemia, nausea and gastrointestinal disorders (181).

A subgroup of patients who completed both trials were successively recruited for the ROMANA 3 study. Patients continued to receive Anamorelin at $100 \mathrm{mg}$ a day or placebo for additional 12 weeks (182). Overall, the treatment was still well tolerated and improvement in body weight and anorexia-cachexia symptoms were significantly increased from baseline of original trials at all time points vs. placebo (182). Nonetheless, the drug has not been approved by FDA since the ROMANA trial did not demonstrated significant benefit handgrip strength, which is one primary outcome required for drug approval.

Further palliative care may be provided by endocannabinoids, i.e., endogenous agonists of the cannabinoid receptors CB1 and CB2. These two receptors are expressed at different levels in both neuronal and non-neuronal tissues, including the gastrointestinal system, SM and AT (207). To date, the endocannabinoid system is known to regulate appetite by differential activation of two brain sites, namely the limbic system and hypothalamus; moreover, it exerts an influence on intestinal and AT functions (207). Among endocannabinoids, $\Delta$-9-tetrahydrocannabinol (THC) was tested as appetite stimulant in a Phase III clinical trial. Although the drug was well tolerated throughout the study, no significant differences were observed in terms of appetite or improvement in QoL between treated patients and the placebo group (183). However, more promising results were obtained by a later trial (184) and a recent pilot study (185) for the same drug. More recently, the synthetic analog of THC nabilone was reported to significantly increase appetite in cachectic NSCLC patients during a Phase II trial, with subsequent increase in patients' caloric intake. The same study reported a significant improvement in patients' QoL and no adverse effects (186).

\section{Erythropoietin}

Anemia is an additional feature displayed by cancer patients who suffer from cachexia, and contributes to weight loss and various metabolic alterations $(187,208)$. Thus, erythropoietin was tested in unselected cancer patients on palliative care. Patients treated with erythropoietin manifested a number of clinical benefits including improved exercise ability and sense of well-being (187). In mouse models of CC, it was shown that treatment with erythropoietin can counteract AT wasting and increase the lipogenic rate through the activation of erythropoietin receptor (EpoR) (208). Moreover, erythropoietin administration improved the survival of cachectic mice along with their exercise capacity, the latter being a consequence of increased erythrocyte count (209). 


\section{New Upcoming Potential Approaches}

Results from latest experimental studies let emerge new potential therapeutics for the clinical management of CC, relying on different strategies than those previously followed (Table 2). For instance, the targeting of endogenous AT and energy metabolism modulators underlying CC may represent a valuable therapeutic option, as in the case of anti-PTHrP antibody (10). Another example is represented by the pharmacological inhibition of fatty acid oxidation by Etoxomir, a carnitine palmitoyltransferase1-selective inhibitor. In a preclinical setting, Etoxomir was shown to effectively rescue human myotubes in vitro as well as muscle mass and body weight of cachectic mice (210). Yet, Metformin was shown to prevent WAT browning by increasing PP2A activity, with subsequent dephosphorylation of acetyl-CoA carboxylase and HSL (211). Targeting of hepatic peroxisome proliferator-activated receptor- $\alpha$ (PPAR $\alpha)$ by PPAR $\alpha$ agonists has also show a considerable potential. In particular, administration of the PPAR $\alpha$ agonist fenofibrate prevented loss of SM mass and body weight in KL mice (152). Moreover, this treatment was capable to reduce elevated glucocorticoid levels in the serum of KL mice, which result from IL-6-induced suppression of hepatic ketogenesis and cause impairment of intratumoral immunity (213).

Further potential drugs that have recently been considered for clinical management of CC belong to the family of histone deacetylase (HDAC) inhibitors. Experimental evidences demonstrated that HDAC1, a class I HDACs family member, is required for muscle atrophy and contractile dysfunction caused by SM disuse and nutrient deprivation, although such mechanism can occur also independently from loss of SM (214). In line with this, a comprehensive study was performed in 2015 showing that AR-42, a novel class I/IIB HDAC inhibitor, displayed anti-cachectic activity in two independent murine models of CC (212). In both models, AR-42 reduced expression of Atrogin-1 and MuRF1 and production of certain proinflammatory cytokines, while significantly improved typical CC features such as body weight loss, reduced survival, muscle and AT loss, reduction of muscle strength, and muscle fiber size (212).

Finally, results obtained from preclinical studies investigating the effects of TLR inhibitors in CC experimental models have raised expectations for the future employment of these drugs in clinical trials (see below), although further investigations on more reliable models of CC are certainly required.

\section{TLR Inhibitors: Novel Therapeutics for Efficient CC Management?}

Involvement of TLRs in muscle atrophy (TLR4 and TLR7/8) and AT remodeling (TLR4) has been highlighted by several in vitro and in vivo studies. These findings led to the development of efficient TLR inhibitors and antagonists, which are currently being considered as part of a new therapeutic strategy against CC. Nonetheless, to date, only a small number of such pharmacological agents is available for clinical use (215).
3-hydroxy-3-methyl-glutaryl-CoA (HMG-CoA) reductase inhibitor, also known as atorvastatin, is a pharmacological inhibitor of TLR4 (74). Atorvastatin impairs the inflammatory pathways through the inhibition of NF- $\kappa$ B activation and downregulation of TLR4 and MyD88 gene expression $(215,216)$. This drug resulted to be a good candidate as potential anticachectic tool since in LLC-bearing mice it significantly prolonged animal survival, increased body weight, impaired AT atrophy and browning and tumor mass compared to untreated animals. Moreover, atorvastatin administration resulted in a decreased concentration of pro-inflammatory cytokines at the plasma level (74).

Several oligonucleotide-based antagonists have been developed to prevent endosomal TLR overactivation in patients with autoimmune diseases (215). Among these, IRS-954 and DV-1179 represent the first two oligonucleotide-based TLR antagonists tested throughout preclinical studies and Phase I/II clinical trials, respectively. However, in spite of the safety shown by these two drugs, none of them were approved for the clinical use due to the lack of adequate documentation (IRS-954) or failure to comply with primary endpoints (215). Few years later, other immune modulatory oligonucleotide (IMO) were developed by Idera Pharmaceuticals with the same goal. Among these, IMO-9200 and IMO8400, two TLR7, 8 and 9-specific antagonists, were tested in clinical trials and the outcomes were more successful than those obtained for DV-1179 (215). However, none of these drugs had yet been considered for clinical management of CC.

In 2018, our group carried out an in vitro and in vivo study in order to test the ability of IMO-8503 to impair miR-21-5pinduced myoblast cell death (75). Results were very encouraging as IMO-8503 significantly inhibited apoptosis induced by lung and pancreatic cell-secreted miR-21-5p and miR-29a-3p on both immortalized and primary myocytes. The same results were obtained with myocytes exposed to cancer patients-derived microvesicles. In vivo, IMO-8503 strongly impaired several cachexia features, including the loss of lean mass in tumorbearing mice (75).

Despite the potential of TLR inhibitors in the management of CC, it should be recalled that also TLR7 agonists have been explored as antitumor agents for treatment of advanced cancers, alone or as vaccine adjuvants. In particular, Imiquimod (R837), a topical TLR7 agonist, was approved by FDA for the treatment of patients with basal cell carcinoma and skin metastases [e.g., (217)]. Imiquimod is generally well-tolerated, with only a minority of patients reporting grade I or II side effects, and lead to significant increases in the activity of both CD8 + and CD4+ T cells. INF $\alpha$ levels were markedly increased in tumor samples from treated patients, while only slight increases were reported for INF $\gamma$ levels (217). Similarly, recent studies have suggested that Resiquimod (R848), a more potent counterpart of Imiquimod, may be beneficial for cancer patients suffering of cachexia (157). R848 is a TLR7 agonist that was proved to cause lower expression of programmed cell death protein 1 (PD-1) on $\mathrm{T}$ cells and enhancement of CD8+ T-cell cytotoxic response in cancer through an IL-12-mediated mechanism (218). R848 was 
TABLE 2 | Table summarizing emergent unimodal treatment options for CC recently tested in preclinical studies.

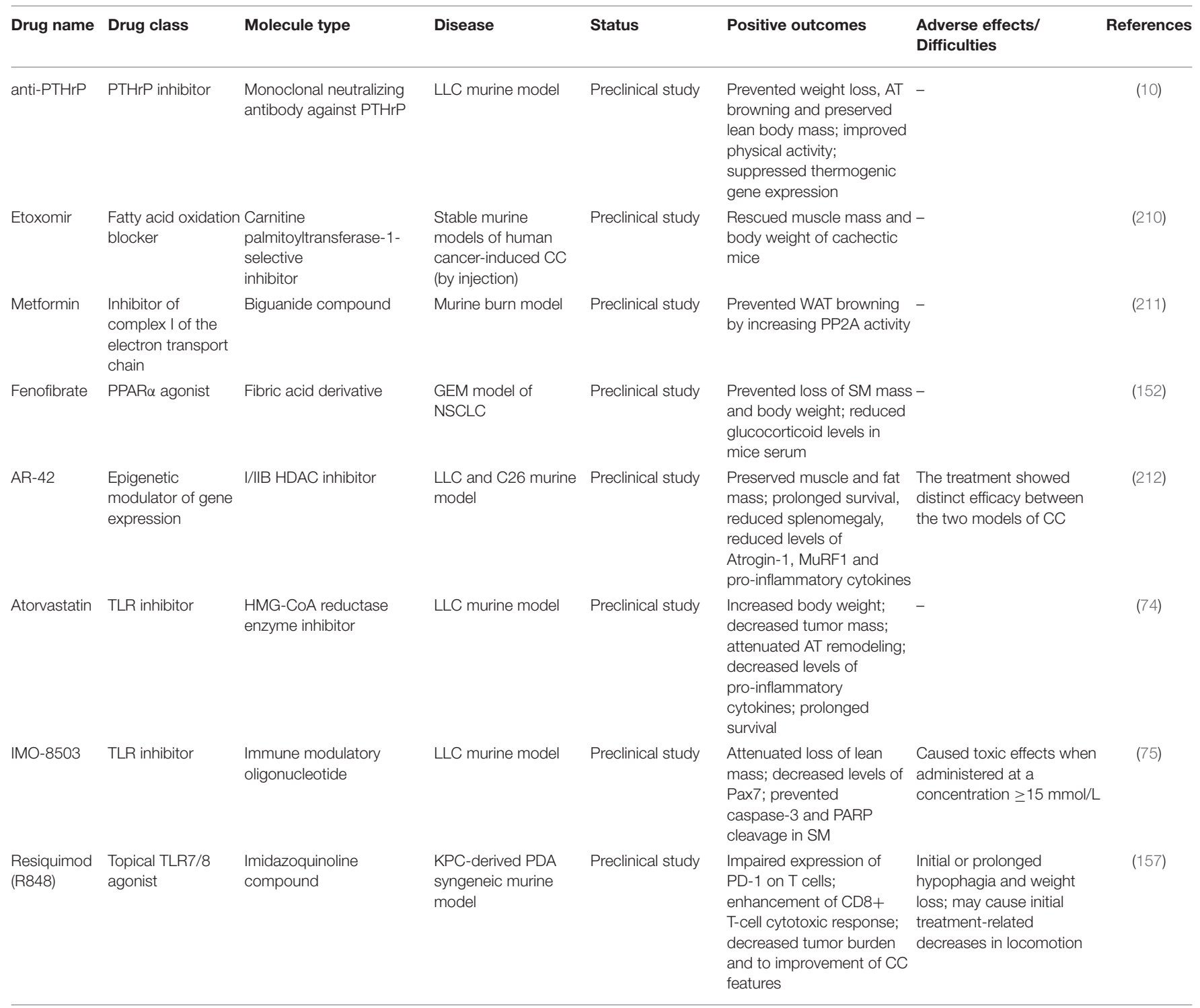

reported to be able to lower tumor burden and improve cachexia manifestations in experimental models of pancreatic ductal adenocarcinoma (157).

\section{CONCLUSIONS}

Over the last two decades, the study of CC has provided new insights that allowed a better understanding of the multiple mechanisms regulating the onset and progression of this metabolic disorder, and paved the way to the development of novel therapeutic strategies. Nonetheless, CC still remains a poorly defined syndrome, especially from the clinical standpoint. The main limitation probably lies in the fact that the precise role of individual CC mediators has remained undefined or controversial in several circumstances, thus complicating the process of establishing their clinical relevance. For instance, not all murine models of CC have shown involvement of the same set of signaling molecules during the disease development. For this reason, the idea of defining distinctive diagnostic and prognostic signatures of CC represents a considerable challenge for researchers and clinicians. In this scenario, the role of miRNAs as cell-to-cell mediators between the tumor cells and the surrounding microenvironment represents an interesting topic that deserves deeper investigation. Overall, these considerations highlight the urgent need to generate and validate new experimental models of CC, capable to accurately recapitulate molecular and histopathological aspects of human $\mathrm{CC}$ in a tumor type-dependent manner.

As systemic chronic inflammation and alternate metabolism are hallmarks of CC, the pharmacological targeting of individual underlying biomolecules has been considered as one possible effective approach to clinically manage this syndrome. Thus, several unimodal treatments have been developed in the attempt to properly manage this metabolic syndrome. Nonetheless, to 
date scarce or no effectiveness/safety has been reported for each of them. Given the complexity of CC, and considering the different patients' response to treatments through the many different clinical trials, it appears clear the impossibility to develop a general, universal therapy. On the contrary, it is crucial to define the cachectic patient's profile at both the molecular and clinical levels in order to reach a point where it is possible to provide the best customized nutritional support and treatment. Meanwhile, the emergence of further mediators of CC such as TLRs, PTHrP, and glucocorticoids, suggests the possibility to develop further safety pharmacological agents capable to prevent, or at least limit, the excessive triggering of catabolic processes and inflammation-related signaling.

Considering the multiplicity of metabolic and molecular aberrations, an important goal would be the development

\section{REFERENCES}

1. Fearon K, Arends J, Baracos V. Understanding the mechanisms and treatment options in cancer cachexia. Nat Rev Clin Oncol. (2013) 10:90-9. doi: 10.1038/nrclinonc.2012.209

2. Schmidt SF, Rohm M, Herzig S, Diaz MB. Cancer cachexia: more than skeletal muscle wasting. Trends Cancer. (2018) 4:849-60. doi: 10.1016/j.trecan.2018.10.001

3. Pin F, Couch ME, Bonetto A. Preservation of muscle mass as a strategy to reduce the toxic effects of cancer chemotherapy on body composition. Curr Opin Support Palliat Care. (2018) 12:420-6. doi: 10.1097/SPC.0000000000000382

4. Evans WJ, Morley JE, Argilés J, Bales C, Baracos V, Guttridge D, et al. Cachexia: a new definition. Clin Nutr. (2008) 27:793-9. doi: 10.1016/j.clnu.2008.06.013

5. Smith KL, Tisdale MJ. Increased protein degradation and decreased protein synthesis in skeletal muscle during cancer cachexia. Br J Cancer. (1993) 67:680-5. doi: 10.1038/bjc.1993.126

6. Tisdale MJ. Cachexia in cancer patients. Nat Rev Cancer. (2002) 2:862-71. doi: $10.1038 / \operatorname{nrc} 927$

7. Penna F, Baccino FM, Costelli P. Coming back: autophagy in cachexia. Curr Opin Clin Nutr Metab Care. (2014) 17:241-6. doi: 10.1097/MCO.0000000000000048

8. Purcell SA, Elliott SA, Baracos VE, Chu QSC, Prado CM. Key determinants of energy expenditure in cancer and implications for clinical practice. Eur J Clin Nutr. (2016) 70:1230-8. doi: 10.1038/ejcn.2016.96

9. Vazeille C, Jouinot A, Durand J-P, Neveux N, Boudou-Rouquette P, Huillard $\mathrm{O}$, et al. Relation between hypermetabolism, cachexia, and survival in cancer patients: a prospective study in 390 cancer patients before initiation of anticancer therapy. Am J Clin Nutr. (2017) 105:1139-47. doi: 10.3945/ajcn.116.140434

10. Kir S, White JP, Kleiner S, Kazak L, Cohen P, Baracos VE, et al. Tumourderived PTH-related protein triggers adipose tissue browning and cancer cachexia. Nature. (2014) 513:100-4. doi: 10.1038/nature13528

11. Petruzzelli M, Schweiger M, Schreiber R, Campos-Olivas R, Tsoli M, Allen J, et al. A switch from white to brown fat increases energy expenditure in cancer-associated cachexia. Cell Metab. (2014) 20:433-47. doi: 10.1016/j.cmet.2014.06.011

12. Zechner R, Zimmermann R, Eichmann TO, Kohlwein SD, Haemmerle G, Lass A, et al. FAT SIGNALS - lipases and lipolysis in lipid metabolism and signaling. Cell Metab. (2012) 15:279-91. doi: 10.1016/j.cmet.2011.12.018

13. Arner P, Langin D. Lipolysis in lipid turnover, cancer cachexia, and obesityinduced insulin resistance. Trends Endocrinol Metab. (2014) 25:255-62. doi: 10.1016/j.tem.2014.03.002

14. Fearon K, Strasser F, Anker SD, Bosaeus I, Bruera E, Fainsinger RL, et al. Definition and classification of cancer cachexia: an international of appropriate multimodal approaches-intended as a balanced combination of pharmacological and nonpharmacological interventions-as recently suggested by several influential authors.

\section{AUTHOR CONTRIBUTIONS}

GM and FC wrote the manuscript. GM, PL, and FC contributed to the editing of the manuscript as needed.

\section{ACKNOWLEDGMENTS}

We thank Prof. Carlo M. Croce for his support in the critical revision of the manuscript.

consensus. Lancet Oncol. (2011) 12:489-95. doi: 10.1016/S1470-2045(10) 70218-7

15. Anker MS, Holcomb R, Muscaritoli M, von Haehling S, Haverkamp W, Jatoi A, et al. Orphan disease status of cancer cachexia in the USA and in the European Union: a systematic review. J Cachexia Sarcopenia Muscle. (2019) 10:22-34. doi: $10.1002 / \mathrm{jcsm} .12402$

16. Arends J, Bachmann P, Baracos V, Barthelemy N, Bertz H, Bozzetti F, et al. ESPEN guidelines on nutrition in cancer patients. Clin Nutr. (2017) 36:11-48. doi: 10.1016/j.clnu.2016.07.015

17. Dewys WD, Begg C, Lavin PT, Band PR, Bennett JM, Bertino JR, et al. Prognostic effect of weight loss prior to chemotherapy in cancer patients. Eastern Cooperative Oncology Group. Am J Med. (1980) 69:491-7. doi: 10.1016/S0149-2918(05)80001-3

18. Hendifar A, Yang D, Lenz F, Lurje G, Pohl A, Lenz C, et al. Gender disparities in metastatic colorectal cancer survival. Clin Cancer Res. (2009) 15:6391-7. doi: 10.1158/1078-0432.CCR-09-0877

19. Baracos VE, Reiman T, Mourtzakis M, Gioulbasanis I, Antoun S. Body composition in patients with non-small cell lung cancer: a contemporary view of cancer cachexia with the use of computed tomography image analysis. Am J Clin Nutr. (2010) 91:1133S-7S. doi: 10.3945/ajen.2010.28608C

20. Baracos VE, Martin L, Korc M, Guttridge DC, Fearon KCH. Cancer-associated cachexia. Nat Rev Dis Primers. (2018) 4:17105. doi: 10.1038/nrdp.2017.105

21. Argilés JM, Moore-Carrasco R, Fuster G, Busquets S, López-Soriano FJ. Cancer cachexia: the molecular mechanisms. Int J Biochem Cell Biol. (2003) 35:405-9. doi: 10.1016/S1357-2725(02)00251-0

22. Prado CMM, Bekaii-Saab T, Doyle LA, Shrestha S, Ghosh S, Baracos VE, et al. Skeletal muscle anabolism is a side effect of therapy with the MEK inhibitor: selumetinib in patients with cholangiocarcinoma. $\mathrm{Br} J$ Cancer. (2012) 106:1583-6. doi: 10.1038/bjc.2012.144

23. Prado CM, Sawyer MB, Ghosh S, Lieffers JR, Esfandiari N, Antoun S, et al. Central tenet of cancer cachexia therapy: do patients with advanced cancer have exploitable anabolic potential? Am J Clin Nutr. (2013) 98:1012-9. doi: $10.3945 /$ ajcn.113.060228

24. Muscaritoli M, Molfino A, Lucia S, Fanelli FR. Cachexia: a preventable comorbidity of cancer. A T.A.R.G.E.T. approach. Crit Rev Oncol Hematol. (2015) 94:251-9. doi: 10.1016/j.critrevonc.2014.10.014

25. Vanhoutte G, van de Wiel M, Wouters K, Sels M, Bartolomeeussen L, De Keersmaecker S, et al. Cachexia in cancer: what is in the definition? BMJ Open Gastroenterol. (2016) 3:e000097. doi: 10.1136/bmjgast-2016-000097

26. Solheim TS, Fayers PM, Fladvad T, Tan B, Skorpen F, Fearon K, et al. Is there a genetic cause for cancer cachexia? - a clinical validation study in 1797 patients. Br J Cancer. (2011) 105:1244-51. doi: 10.1038/bjc.2011.323

27. Johns N, Stretch C, Tan BHL, Solheim TS, Sørhaug S, Stephens NA, et al. New genetic signatures associated with cancer cachexia as defined by low 
skeletal muscle index and weight loss. J Cachexia Sarcopenia Muscle. (2017) 8:122-30. doi: 10.1002/jcsm. 12138

28. Borish LC, Steinke JW. 2. Cytokines and chemokines. J Allergy Clin Immunol. (2003) 111:S460-75. doi: 10.1067/mai.2003.108

29. Seruga B, Zhang H, Bernstein LJ, Tannock IF. Cytokines and their relationship to the symptoms and outcome of cancer. Nat Rev Cancer. (2008) 8:887-99. doi: 10.1038/nrc2507

30. Serhan CN, Brain SD, Buckley CD, Gilroy DW, Haslett C, O'Neill LAJ, et al. Resolution of inflammation: state of the art, definitions and terms. FASEB J. (2007) 21:325-32. doi: 10.1096/fj.06-7227rev

31. Advani SM, Advani PG, VonVille HM, Jafri SH. Pharmacological management of cachexia in adult cancer patients: a systematic review of clinical trials. BMC Cancer. (2018) 18:1174. doi: 10.1186/s12885-018-5080-4

32. Beutler B, Cerami A. Cachectin and tumour necrosis factor as two sides of the same biological coin. Nature. (1986) 320:584-8. doi: 10.1038/320584a0

33. Oliff A, Defeo-Jones D, Boyer M, Martinez D, Kiefer D, Vuocolo G, et al. Tumors secreting human TNF/cachectin induce cachexia in mice. Cell. (1987) 50:555-63. doi: 10.1016/0092-8674(87)90028-6

34. Aggarwal BB. Signalling pathways of the TNF superfamily: a double-edged sword. Nat Rev Immunol. (2003) 3:745-56. doi: 10.1038/nri1184

35. Guttridge DC, Mayo MW, Madrid LV, Wang CY, Baldwin AS Jr. NF-kappaBinduced loss of MyoD messenger RNA: possible role in muscle decay and cachexia. Science. (2000) 289:2363-6. doi: 10.1126/science.289.5488.2363

36. Ruan H, Hacohen N, Golub TR, Van Parijs L, Lodish HF. Tumor necrosis factor-alpha suppresses adipocyte-specific genes and activates expression of preadipocyte genes in 3T3-L1 adipocytes: nuclear factorkappaB activation by TNF-alpha is obligatory. Diabetes. (2002) 51:1319-36. doi: $10.2337 /$ diabetes.51.5.1319

37. Li YP, Schwartz RJ, Waddell ID, Holloway BR, Reid MB. Skeletal muscle myocytes undergo protein loss and reactive oxygen-mediated NF-kappaB activation in response to tumor necrosis factor alpha. FASEB J. (1998) 12:871-80. doi: 10.1096/fasebj.12.10.871

38. Li Y-P, Reid MB. NF- $\kappa$ B mediates the protein loss induced by TNF- $\alpha$ in differentiated skeletal muscle myotubes. Am J Physiol Regul Integr Comp Physiol. (2000) 279:R1165-70. doi: 10.1152/ajpregu.2000.279.4.R1165

39. Acharyya S, Ladner KJ, Nelsen LL, Damrauer J, Reiser PJ, Swoap S, et al. Cancer cachexia is regulated by selective targeting of skeletal muscle gene products. J Clin Invest. (2004) 114:370-8. doi: 10.1172/JCI200 420174

40. Dogra C, Changotra H, Wedhas N, Qin X, Wergedal JE, Kumar A. TNFrelated weak inducer of apoptosis. (TWEAK) is a potent skeletal musclewasting cytokine. FASEB J. (2007) 21:1857-69. doi: 10.1096/fj.06-7537com

41. Mittal A, Bhatnagar S, Kumar A, Lach-Trifilieff E, Wauters S, Li H, et al. The TWEAK-Fn14 system is a critical regulator of denervationinduced skeletal muscle atrophy in mice. J Cell Biol. (2010) 188:833-49. doi: $10.1083 /$ jcb. 200909117

42. Strassmann G, Fong M, Kenney JS, Jacob CO. Evidence for the involvement of interleukin 6 in experimental cancer cachexia. J Clin Invest. (1992) 89:1681-4. doi: 10.1172/JCI115767

43. White JP, Baynes JW, Welle SL, Kostek MC, Matesic LE, Sato S, et al. The regulation of skeletal muscle protein turnover during the progression of cancer cachexia in the ApcMin/mouse. PLoS ONE. (2011) 6:e24650. doi: 10.1371/journal.pone.0024650

44. Strassmann G, Fong M, Freter CE, Windsor S, D'Alessandro F, Nordan RP. Suramin interferes with interleukin-6 receptor binding in vitro and inhibits colon-26-mediated experimental cancer cachexia in vivo. J Clin Invest. (1993) 92:2152-9. doi: 10.1172/JCI116816

45. Auernhammer CJ, Melmed S. Leukemia-inhibitory factor-neuroimmune modulator of endocrine function. Endocr Rev. (2000) 21:313-45. doi: $10.1210 /$ er.21.3.313

46. Hu W, Feng Z, Teresky AK, Levine AJ. p53 regulates maternal reproduction through LIF. Nature. (2007) 450:721-4. doi: 10.1038/nature05993

47. Metcalf D, Gearing DP. Fatal syndrome in mice engrafted with cells producing high levels of the leukemia inhibitory factor. Proc Natl Acad Sci USA. (1989) 86:5948-52. doi: 10.1073/pnas.86.15.5948

48. Akiyama Y, Kajimura N, Matsuzaki J, Kikuchi Y, Imai N, Tanigawa M, et al. In vivo effect of recombinant human leukemia inhibitory factor in primates.
Jpn J Cancer Res. (1997) 88:578-83. doi: 10.1111/j.1349-7006.1997.tb 00421.x

49. Seto DN, Kandarian SC, Jackman RW. A key role for leukemia inhibitory factor in C26 cancer cachexia. J Biol Chem. (2015) 290:19976-86. doi: 10.1074/jbc.M115.638411

50. Arora GK, Gupta A, Narayanan S, Guo T, Iyengar P, Infante RE. Cachexiaassociated adipose loss induced by tumor-secreted leukemia inhibitory factor is counterbalanced by decreased leptin. JCI Insight. (2018) 3:121221. doi: $10.1172 /$ jci.insight.121221

51. Baracos V, Rodemann HP, Dinarello CA, Goldberg AL. Stimulation of muscle protein degradation and prostaglandin E2 release by leukocytic pyrogen. (interleukin-1). A mechanism for the increased degradation of muscle proteins during fever. N Engl J Med. (1983) 308:553-8. doi: 10.1056/NEJM198303103081002

52. Fong Y, Moldawer LL, Marano M, Wei H, Barber A, Manogue K, et al. Cachectin/TNF or IL-1 alpha induces cachexia with redistribution of body proteins. Am J Physiol Regul Integr Comp Physiol. (1989) 256:R659-65. doi: 10.1152/ajpregu.1989.256.3.R659

53. Gelin J, Moldawer LL, Lönnroth C, Sherry B, Chizzonite R, Lundholm $\mathrm{K}$. Role of endogenous tumor necrosis factor alpha and interleukin 1 for experimental tumor growth and the development of cancer cachexia. Cancer Res. (1991) 51:415-21.

54. Braun TP, Zhu X, Szumowski M, Scott GD, Grossberg AJ, Levasseur PR, et al. Central nervous system inflammation induces muscle atrophy via activation of the hypothalamic-pituitary-adrenal axis. J Exp Med. (2011) 208:2449-63. doi: 10.1084 /jem.20111020

55. Robert F, Mills JR, Agenor A, Wang D, DiMarco S, Cencic R, et al. Targeting protein synthesis in a Myc/mTOR-driven model of anorexiacachexia syndrome delays its onset and prolongs survival. Cancer Res. (2012) 72:747-56. doi: 10.1158/0008-5472.CAN-11-2739

56. Akdis M, Burgler S, Crameri R, Eiwegger T, Fujita H, Gomez E, et al. Interleukins, from 1 to 37 , and interferon- $\gamma$ : Receptors, functions, and roles in diseases. J Aller Clin Immunol. (2011) 127:701-21.e70. doi: 10.1016/j.jaci.2010.11.050

57. Ramani P, Balkwill FR. Enhanced metastases of a mouse carcinoma after in vitro treatment with murine interferon gamma. Int J Cancer. (1987) 40:830-4. doi: 10.1002/ijc.2910400621

58. Ferrantini M, Giovarelli M, Modesti A, Musiani P, Modica A, Venditti M, et al. IFN-alpha 1 gene expression into a metastatic murine adenocarcinoma. (TS/A) results in CD8 $+\mathrm{T}$ cell-mediated tumor rejection and development of antitumor immunity. Comparative studies with IFN-gamma-producing TS/A cells. J Immunol. (1994) 153:4604-15.

59. Billiau A, Matthys P. Interferon- $\gamma$, more of a cachectin than tumor necrosis factor. Cytokine. (1992) 4:259-63. doi: 10.1016/1043-4666(92)90065-Y

60. Matthys P, Dijkmans R, Proost P, Van Damme J, Heremans H, Sobis H, et al. Severe cachexia in mice inoculated with interferon-gamma-producing tumor cells. Int J Cancer. (1991) 49:77-82. doi: 10.1002/ijc.2910490115

61. Matthys P, Heremans H, Opdenakker G, Billiau A. Anti-interferon$\gamma$ antibody treatment, growth of Lewis lung tumours in mice and tumour-associated cachexia. Eur J Cancer Clin Oncol. (1991) 27:182-7. doi: 10.1016/0277-5379(91)90483-T

62. Iorio MV, Croce CM. Causes and consequences of MicroRNA dysregulation. Cancer J. (2012) 18:215-22. doi: 10.1097/PPO.0b013e318250c001

63. Nana-Sinkam SP, Croce CM. Clinical applications for microRNAs in cancer. Clin Pharmacol Ther. (2013) 93:98-104. doi: 10.1038/clpt.2012.192

64. O’Brien J, Hayder H, Zayed Y, Peng C. Overview of MicroRNA biogenesis, mechanisms of actions, and circulation. Front Endocrinol. (2018) 9:402. doi: 10.3389/fendo.2018.00402

65. Zhou W, Fong MY, Min Y, Somlo G, Liu L, Palomares MR, et al. Cancer-secreted miR-105 destroys vascular endothelial barriers to promote metastasis. Cancer Cell. (2014) 25:501-15. doi: 10.1016/j.ccr.2014.03.007

66. He WA, Calore F, Londhe P, Canella A, Guttridge DC, Croce CM. Microvesicles containing miRNAs promote muscle cell death in cancer cachexia via TLR7. Proc Natl Acad Sci USA. (2014) 111:4525-9. doi: 10.1073/pnas.1402714111

67. Okugawa Y, Toiyama Y, Hur K, Yamamoto A, Yin C, Ide S, et al. Circulating miR-203 derived from metastatic tissues promotes myopenia in 
colorectal cancer patients. J Cachexia Sarcopenia Muscle. (2019) 10:536-48. doi: $10.1002 /$ jcsm. 12403

68. Soares RJ, Cagnin S, Chemello F, Silvestrin M, Musaro A, De Pitta $\mathrm{C}$, et al. Involvement of microRNAs in the regulation of muscle wasting during catabolic conditions. J Biol Chem. (2014) 289:21909-25. doi: 10.1074/jbc.M114.561845

69. Wu Q, Sun S, Li Z, Yang Q, Li B, Zhu S, et al. Tumour-originated exosomal miR-155 triggers cancer-associated cachexia to promote tumour progression. Mol Cancer. (2018) 17:155. doi: 10.1186/s12943-018-0899-5

70. Gay NJ, Symmons MF, Gangloff M, Bryant CE. Assembly and localization of Toll-like receptor signalling complexes. Nat Rev Immunol. (2014) 14:546-58. doi: $10.1038 /$ nri3713

71. Bohnert KR, Goli P, Roy A, Sharma AK, Xiong G, Gallot YS, et al. The toll-like receptor/MyD88/XBP1 signaling axis mediates skeletal muscle wasting during cancer cachexia. Mol Cell Biol. (2019) 39: e00184-19. doi: 10.1128/MCB.00184-19

72. Doyle A, Zhang G, Abdel Fattah EA, Eissa NT, Li Y-P. Toll-like receptor 4 mediates lipopolysaccharide-induced muscle catabolism via coordinate activation of ubiquitin-proteasome and autophagy-lysosome pathways. FASEB J. (2011) 25:99-110. doi: 10.1096/fj.10-164152

73. Zhang G, Liu Z, Ding H, Zhou Y, Doan HA, Sin KWT, et al. Tumor induces muscle wasting in mice through releasing extracellular Hsp70 and Hsp90. Nat Commun. (2017) 8:589. doi: 10.1038/s41467-017-00726-x

74. Henriques F, Lopes MA, Franco FO, Knobl P, Santos KB, Bueno LL, et al. Toll-like receptor-4 disruption suppresses adipose tissue remodeling and increases survival in cancer cachexia syndrome. Sci Rep. (2018) 8:18024. doi: 10.1038/s41598-018-36626-3

75. Calore F, Londhe P, Fadda P, Nigita G, Casadei L, Marceca GP, et al. The TLR7/8/9 antagonist IMO-8503 inhibits cancer-induced cachexia. Cancer Res. (2018) 78:6680-90. doi: 10.1158/0008-5472.CAN-17-3878

76. Terawaki K, Kashiwase Y, Uzu M, Nonaka M, Sawada Y, Miyano $\mathrm{K}$, et al. Leukemia inhibitory factor via the Toll-like receptor 5 signaling pathway involves aggravation of cachexia induced by human gastric cancer-derived 85As2 cells in rats. Oncotarget. (2018) 9:34748-64. doi: 10.18632 /oncotarget. 26190

77. Morvan F, Rondeau J-M, Zou C, Minetti G, Scheufler C, Scharenberg M, et al. Blockade of activin type II receptors with a dual anti-ActRIIA/IIB antibody is critical to promote maximal skeletal muscle hypertrophy. Proc Natl Acad Sci USA. (2017) 114:12448-53. doi: 10.1073/pnas.1707925114

78. Joulia-Ekaza D, Cabello G. The myostatin gene: physiology and pharmacological relevance. Curr Opin Pharmacol. (2007) 7:310-5. doi: 10.1016/j.coph.2006.11.011

79. Zimmers TA, Davies MV, Koniaris LG, Haynes P, Esquela AF, Tomkinson $\mathrm{KN}$, et al. Induction of cachexia in mice by systemically administered myostatin. Science. (2002) 296:1486-8. doi: 10.1126/science.1069525

80. Bogdanovich S, Krag TOB, Barton ER, Morris LD, Whittemore L-A, Ahima RS, et al. Functional improvement of dystrophic muscle by myostatin blockade. Nature. (2002) 420:418-21. doi: 10.1038/nature01154

81. Welle S, Bhatt K, Pinkert CA, Tawil R, Thornton CA. Muscle growth after postdevelopmental myostatin gene knockout. Am J Physiol Endocrinol Metab. (2007) 292:E985-91. doi: 10.1152/ajpendo.00531.2006

82. Costelli P, Muscaritoli M, Bonetto A, Penna F, Reffo P, Bossola M, et al. Muscle myostatin signalling is enhanced in experimental cancer cachexia. Eur J Clin Invest. (2008) 38:531-8. doi: 10.1111/j.1365-2362.2008.01970.x

83. Liu C-M, Yang Z, Liu C-W, Wang R, Tien P, Dale R, et al. Myostatin antisense RNA-mediated muscle growth in normal and cancer cachexia mice. Gene Ther. (2008) 15:155-60. doi: 10.1038/sj.gt.3303016

84. Xia Y, Schneyer AL. The biology of activin: recent advances in structure, regulation and function. J Endocrinol. (2009) 202:1-12. doi: 10.1677/JOE-08-0549

85. Hedger MP, de Kretser DM. The activins and their binding protein, follistatin-Diagnostic and therapeutic targets in inflammatory disease and fibrosis. Cytok Growth Factor Rev. (2013) 24:285-95. doi: 10.1016/j.cytogfr.2013.03.003

86. Leto G, Incorvaia L, Badalamenti G, Tumminello FM, Gebbia N, Flandina $\mathrm{C}$, et al. Activin A circulating levels in patients with bone metastasis from breast or prostate cancer. Clin Exp Metast. (2006) 23:117-22. doi: $10.1007 / \mathrm{s} 10585-006-9010-5$
87. Zhou X, Wang JL, Lu J, Song Y, Kwak KS, Jiao Q, et al. Reversal of cancer cachexia and muscle wasting by ActRIIB antagonism leads to prolonged survival. Cell. (2010) 142:531-43. doi: 10.1016/j.cell.2010.07.011

88. Chen JL, Walton KL, Winbanks CE, Murphy KT, Thomson RE, Makanji Y, et al. Elevated expression of activins promotes muscle wasting and cachexia. FASEB J. (2014) 28:1711-23. doi: 10.1096/fj.13-245894

89. Busquets S, Toledo M, Orpí M, Massa D, Porta M, Capdevila E, et al. Myostatin blockage using actRIIB antagonism in mice bearing the Lewis lung carcinoma results in the improvement of muscle wasting and physical performance. J Cachexia Sarcopenia Muscle. (2012) 3:37-43. doi: 10.1007/s13539-011-0049-z

90. Kir S, Komaba H, Garcia AP, Economopoulos KP, Liu W, Lanske B, et al. PTH/PTHrP receptor mediates cachexia in models of kidney failure and cancer. Cell Metab. (2016) 23:315-23. doi: 10.1016/j.cmet.2015.11.003

91. Vilardaga J-P, Romero G, Friedman PA, Gardella TJ. Molecular basis of parathyroid hormone receptor signaling and trafficking: a family B GPCR paradigm. Cell Mol Life Sci. (2011) 68:1-13. doi: 10.1007/s00018-010-0465-9

92. Bao Y, Bing C, Hunter L, Jenkins JR, Wabitsch M, Trayhurn P. Zinc-alpha2-glycoprotein, a lipid mobilizing factor, is expressed and secreted by human. (SGBS) adipocytes. FEBS Lett. (2005) 579:41-7. doi: 10.1016/j.febslet.2004.11.042

93. Bing C, Bao Y, Jenkins J, Sanders P, Manieri M, Cinti S, et al. Zinc- 2glycoprotein, a lipid mobilizing factor, is expressed in adipocytes and is up-regulated in mice with cancer cachexia. Proc Natl Acad Sci USA. (2004) 101:2500-5. doi: 10.1073/pnas.0308647100

94. Rydén M, Agustsson T, Andersson J, Bolinder J, Toft E, Arner P. Adipose zinc- $\alpha 2$-glycoprotein is a catabolic marker in cancer and noncancerous states. J Intern Med. (2012) 271:414-20. doi: 10.1111/j.1365-2796.2011.02441.x

95. Russell ST, Zimmerman TP, Domin BA, Tisdale MJ. Induction of lipolysis in vitro and loss of body fat in vivo by zinc- $\alpha 2$-glycoprotein. Biochim Biophys Acta. Mol Cell Biol Lipids. (2004) 1636:59-68. doi: 10.1016/j.bbalip.2003.12.004

96. Russell ST, Tisdale MJ. Effect of eicosapentaenoic acid. (EPA) on expression of a lipid mobilizing factor in adipose tissue in cancer cachexia. Prostaglandins Leukot Essent Fatty Acids. (2005) 72:409-14. doi: 10.1016/j.plefa.2005.03.002

97. Rolli V, Radosavljevic M, Astier V, Macquin C, Castan-Laurell I, Visentin $\mathrm{V}$, et al. Lipolysis is altered in MHC class I zinc- $\alpha 2$-glycoprotein deficient mice. FEBS Lett. (2007) 581:394-400. doi: 10.1016/j.febslet.2006. 12.047

98. Argilés JM, López-Soriano FJ. The ubiquitin-dependent proteolytic pathway in skeletal muscle: its role in pathological states. Trends Pharmacol Sci. (1996) 17:223-6. doi: 10.1016/0165-6147(96)10021-3

99. Glass DJ. Signaling pathways perturbing muscle mass. Curr Opin Clin Nutr Metab Care. (2010) 13:225-9. doi: 10.1097/MCO.0b013e32833862df

100. Zhang G, Jin B, Li Y-P. C/EBP $\beta$ mediates tumour-induced ubiquitin ligase atrogin1/MAFbx upregulation and muscle wasting. EMBO J. (2011) 30:4323-35. doi: 10.1038/emboj.2011.292

101. He WA, Berardi E, Cardillo VM, Acharyya S, Aulino P, ThomasAhner J, et al. NF-kB-mediated Pax7 dysregulation in the muscle microenvironment promotes cancer cachexia. J Clin Invest. (2013) 123:482135. doi: 10.1172/JCI68523

102. Zimmers TA, Fishel ML, Bonetto A. STAT3 in the systemic inflammation of cancer cachexia. Semin Cell Dev Biol. (2016) 54:28-41. doi: $10.1016 / j . s e m c d b .2016 .02 .009$

103. Ma JF, Sanchez BJ, Hall DT, Tremblay AK, Di Marco S, Gallouzi I. STAT 3 promotes IFN $\gamma /$ TNF $\alpha$-induced muscle wasting in an NF -кBdependent and IL-6-independent manner. EMBO Mol Med. (2017) 9:62237. doi: 10.15252/emmm.201607052

104. Stitt TN, Drujan D, Clarke BA, Panaro F, Timofeyva Y, Kline WO, et al. The IGF-1/PI3K/Akt pathway prevents expression of muscle atrophy-induced ubiquitin ligases by inhibiting FOXO transcription factors. Mol Cell. (2004) 14:395-403. doi: 10.1016/S1097-2765(04)00211-4

105. Sandri M, Sandri C, Gilbert A, Skurk C, Calabria E, Picard A, et al. Foxo transcription factors induce the atrophy-related ubiquitin ligase atrogin-1 and cause skeletal muscle atrophy. Cell. (2004) 117:399-412. doi: $10.1016 /$ S0092-8674(04)00400-3 
106. Ben-Sahra I, Manning BD. mTORC1 signaling and the metabolic control of cell growth. Curr Opin Cell Biol. (2017) 45:72-82. doi: 10.1016/j.ceb.2017.02.012

107. Song Y-H, Li Y, Du J, Mitch WE, Rosenthal N, Delafontaine P. Muscle-specific expression of IGF-1 blocks angiotensin II-induced skeletal muscle wasting. J Clin Investig. (2005) 115:451-8. doi: 10.1172/JCI 22324

108. Milan G, Romanello V, Pescatore F, Armani A, Paik J-H, Frasson L, et al. Regulation of autophagy and the ubiquitin-proteasome system by the FoxO transcriptional network during muscle atrophy. Nat Commun. (2015) 6:6670. doi: 10.1038/ncomms7670

109. Sandri M, Lin J, Handschin C, Yang W, Arany ZP, Lecker SH, et al. PGC1alpha protects skeletal muscle from atrophy by suppressing FoxO3 action and atrophy-specific gene transcription. Proc Natl Acad Sci USA. (2006) 103:16260-5. doi: 10.1073/pnas.0607795103

110. Patra MC, Shah M, Choi S. Toll-like receptor-induced cytokines as immunotherapeutic targets in cancers and autoimmune diseases. Semin Cancer Biol. (in press). doi: 10.1016/j.semcancer.2019.05.002

111. Wang EL, Qian ZR, Nakasono M, Tanahashi T, Yoshimoto K, Bando Y, et al. High expression of Toll-like receptor 4/myeloid differentiation factor 88 signals correlates with poor prognosis in colorectal cancer. Br J Cancer. (2010) 102:908-15. doi: 10.1038/sj.bjc.6605558

112. Sun Q, Liu Q, Zheng Y, Cao X. Rapamycin suppresses TLR4-triggered IL-6 and PGE2 production of colon cancer cells by inhibiting TLR4 expression and NF-kB activation. Mol Immunol. (2008) 45:2929-36. doi: 10.1016/j.molimm.2008.01.025

113. Kundu SD, Lee C, Billips BK, Habermacher GM, Zhang Q, Liu V, et al. The toll-like receptor pathway: a novel mechanism of infectioninduced carcinogenesis of prostate epithelial cells. Prostate. (2008) 68:223-9. doi: $10.1002 /$ pros. 20710

114. Killeen SD, Wang JH, Andrews EJ, Redmond HP. Bacterial endotoxin enhances colorectal cancer cell adhesion and invasion through TLR-4 and NF-KB-dependent activation of the urokinase plasminogen activator system. Br J Cancer. (2009) 100:1589-602. doi: 10.1038/sj.bjc.6604942

115. Argilés JM, Orpí M, Busquets S, López-Soriano FJ. Myostatin: more than just a regulator of muscle mass. Drug Discov Today. (2012) 17:702-9. doi: 10.1016/j.drudis.2012.02.001

116. Kemaladewi DU, de Gorter DJJ, Aartsma-Rus A, van Ommen G-J, ten Dijke $\mathrm{P}$, 't PA, et al. Cell-type specific regulation of myostatin signaling. FASEB J. (2012) 26:1462-72. doi: 10.1096/fj.11-191189

117. Penna F, Costamagna D, Pin F, Camperi A, Fanzani A, Chiarpotto EM, et al. Autophagic degradation contributes to muscle wasting in cancer cachexia. Am J Pathol. (2013) 182:1367-78. doi: 10.1016/j.ajpath.2012. 12.023

118. Tardif N, Klaude M, Lundell L, Thorell A, Rooyackers O. Autophagiclysosomal pathway is the main proteolytic system modified in the skeletal muscle of esophageal cancer patients. Am J Clin Nutr. (2013) 98:1485-92. doi: 10.3945/ajcn.113.063859

119. Aversa Z, Pin F, Lucia S, Penna F, Verzaro R, Fazi M, et al. Autophagy is induced in the skeletal muscle of cachectic cancer patients. Sci Rep. (2016) 6:30340. doi: 10.1038/srep30340

120. Pigna E, Berardi E, Aulino P, Rizzuto E, Zampieri S, Carraro U, et al. Aerobic exercise and pharmacological treatments counteract cachexia by modulating autophagy in colon cancer. Sci Rep. (2016) 6:26991. doi: 10.1038/srep26991

121. Liu Z, Sin KWT, Ding H, Doan HA, Gao S, Miao H, et al. p38 $\beta$ MAPK mediates ULK1-dependent induction of autophagy in skeletal muscle of tumor-bearing mice. Cell Stress Chaperones. (2018) 2:311-24. doi: $10.15698 / \operatorname{cst} 2018.11 .163$

122. Coppack SW. Pro-inflammatory cytokines and adipose tissue. Proc Nutr Soc. (2001) 60:349-56. doi: 10.1079/PNS2001110

123. Mead JR, Irvine SA, Ramji DP. Lipoprotein lipase: structure, function, regulation, and role in disease. J Mol Med. (2002) 80:753-69. doi: $10.1007 / \mathrm{s} 00109-002-0384-9$

124. Thompson MP, Cooper ST, Parry BR, Tuckey JA. Increased expression of the mRNA for hormone-sensitive lipase in adipose tissue of cancer patients. Biochim Biophys Acta. (1993) 1180:236-42. doi: 10.1016/0925-4439(93)90044-2
125. Beck SA, Tisdale MJ. Effect of cancer cachexia on triacylglycerol/fatty acid substrate cycling in white adipose tissue. Lipids. (2004) 39:1187-9. doi: 10.1007/s11745-004-1346-8

126. Zhang HH, Halbleib M, Ahmad F, Manganiello VC, Greenberg AS, Tumor necrosis factor- stimulates lipolysis in differentiated human adipocytes through activation of extracellular signal-related kinase and elevation of intracellular cAMP. Diabetes. (2002) 51:2929-35. doi: 10.2337/diabetes.51.10.2929

127. Hirai K, Hussey HJ, Barber MD, Price SA, Tisdale MJ. Biological evaluation of a lipid-mobilizing factor isolated from the urine of cancer patients. Cancer Res. (1998) 58:2359-65.

128. Islam-Ali B, Khan S, Price SA, Tisdale MJ. Modulation of adipocyte Gprotein expression in cancer cachexia by a lipid-mobilizing factor. (LMF). Br J Cancer. (2001) 85:758-63. doi: 10.1054/bjoc.2001.1992

129. Tsoli M, Schweiger M, Vanniasinghe AS, Painter A, Zechner R, Clarke S, et al. Depletion of white adipose tissue in cancer cachexia syndrome is associated with inflammatory signaling and disrupted circadian regulation. PLOS ONE. (2014) 9:e92966. doi: 10.1371/journal.pone.0092966

130. Lowell BB, Spiegelman BM. Towards a molecular understanding of adaptive thermogenesis. Nature. (2000) 404:652-60. doi: 10.1038/35007527

131. Bing C, Brown M, King P, Collins P, Tisdale MJ, Williams G. Increased gene expression of brown fat uncoupling protein. (UCP)1 and skeletal muscle UCP2 and UCP3 in MAC16-induced cancer cachexia. Cancer Res. (2000) 60:2405-10. doi: 10.1042/cs098001Pa

132. Collins P, Bing C, McCulloch P, Williams G. Muscle UCP-3 mRNA levels are elevated in weight loss associated with gastrointestinal adenocarcinoma in humans. Br J Cancer. (2002) 86:372-5. doi: 10.1038/sj.bjc.6600074

133. Kliewer KL, Ke J-Y, Tian M, Cole RM, Andridge RR, Belury MA. Adipose tissue lipolysis and energy metabolism in early cancer cachexia in mice. Cancer Biol Ther. (2015) 16:886-97. doi: 10.4161/15384047.2014. 987075

134. Petrovic N, Walden TB, Shabalina IG, Timmons JA, Cannon B, Nedergaard J. Chronic peroxisome proliferator-activated receptor $\gamma$. (PPAR $\gamma$ ) activation of epididymally derived white adipocyte cultures reveals a population of thermogenically competent, UCP1-containing adipocytes molecularly distinct from classic brown adipocytes. J Biol Chem. (2010) 285:7153-64. doi: 10.1074/jbc.M109.053942

135. Villarroya F, Cereijo R, Villarroya J, Giralt M. Brown adipose tissue as a secretory organ. Nat Rev Endocrinol. (2017) 13:26-35. doi: 10.1038/nrendo.2016.136

136. Kimura S, Yoshioka K. Parathyroid hormone and parathyroid hormone type-1 receptor accelerate myocyte differentiation. Sci Rep. (2014) 4:5066. doi: $10.1038 /$ srep05066

137. Tsoli M, Moore M, Burg D, Painter A, Taylor R, Lockie SH, et al. Activation of thermogenesis in brown adipose tissue and dysregulated lipid metabolism associated with cancer cachexia in mice. Cancer Res. (2012) 72:4372-82. doi: 10.1158/0008-5472.CAN-11-3536

138. Cao W, Daniel KW, Robidoux J, Puigserver P, Medvedev AV, Bai X, et al. p38 mitogen-activated protein kinase is the central regulator of cyclic AMPdependent transcription of the brown fat uncoupling protein 1 gene. Mol Cell Biol. (2004) 24:3057-67. doi: 10.1128/MCB.24.7.3057-3067.2004

139. Li G, Klein RL, Matheny M, King MA, Meyer EM, Scarpace PJ. Induction of uncoupling protein 1 by central interleukin- 6 gene delivery is dependent on sympathetic innervation of brown adipose tissue and underlies one mechanism of body weight reduction in rats. Neuroscience. (2002) 115:87989. doi: $10.1016 / \mathrm{S} 0306-4522(02) 00447-5$

140. Wallenius K, Wallenius V, Sunter D, Dickson SL, Jansson J-O. Intracerebroventricular interleukin-6 treatment decreases body fat in rats. Biochem Biophys Res Commun. (2002) 293:560-5. doi: 10.1016/S0006-291X(02)00230-9

141. Nguyen KD, Qiu Y, Cui X, Goh YPS, Mwangi J, David T, et al Alternatively activated macrophages produce catecholamines to sustain adaptive thermogenesis. Nature. (2011) 480:104-8. doi: 10.1038/nature10653

142. Mauer J, Chaurasia B, Goldau J, Vogt MC, Ruud J, Nguyen KD, et al. Signaling by IL-6 promotes alternative activation of macrophages to limit endotoxemia and obesity-associated resistance to insulin. Nat Immunol. (2014) 15:423-30. doi: 10.1038/ni.2865 
143. Baracos VE. Bridging the gap: are animal models consistent with clinical cancer cachexia? Nat Rev Clin Oncol. (2018) 15:197-8. doi: 10.1038/nrclinonc.2018.14

144. Talbert EE, Cuitiño MC, Ladner KJ, Rajasekerea PV, Siebert M, Shakya R, et al. Modeling human cancer-induced cachexia. Cell Rep. (2019) 28:161222.e4. doi: 10.1016/j.celrep.2019.07.016

145. Cernackova A, Mikova L, Horvathova L, Tillinger A, Mravec B. Cachexia induced by Yoshida ascites hepatoma in Wistar rats is not associated with inflammatory response in the spleen or brain. J Neuroimmunol. (2019) 337:577068. doi: 10.1016/j.jneuroim.2019.577068

146. Vooijs M, Jonkers J, Berns A. A highly efficient ligand-regulated Cre recombinase mouse line shows that LoxP recombination is position dependent. EMBO Rep. (2001) 2:292-7. doi: 10.1093/embo-reports/kve064

147. Branda CS, Dymecki SM. Talking about a revolution. Dev Cell. (2004) 6:7-28. doi: 10.1016/S1534-5807(03)00399-X

148. Kristianto J, Johnson MG, Zastrow RK, Radcliff AB, Blank RD. Spontaneous recombinase activity of Cre-ERT2 in vivo. Trans Res. (2017) 26:411-7. doi: 10.1007/s11248-017-0018-1

149. Hingorani SR, Wang L, Multani AS, Combs C, Deramaudt TB, Hruban $\mathrm{RH}$, et al. Trp53R172H and KrasG12D cooperate to promote chromosomal instability and widely metastatic pancreatic ductal adenocarcinoma in mice. Cancer Cell. (2005) 7:469-83. doi: 10.1016/j.ccr.2005.04.023

150. Michaelis KA, Zhu X, Burfeind KG, Krasnow SM, Levasseur PR, Morgan TK, et al. Establishment and characterization of a novel murine model of pancreatic cancer cachexia. J Cachexia Sarcopenia Muscle. (2017) 8:824-38. doi: $10.1002 /$ jcsm. 12225

151. Parajuli P, Kumar S, Loumaye A, Singh P, Eragamreddy S, Nguyen TL, et al. Twist 1 activation in muscle progenitor cells causes muscle loss akin to cancer cachexia. Dev Cell. (2018) 45:712-25.e6. doi: 10.1016/j.devcel.2018.05.026

152. Goncalves MD, Hwang S-K, Pauli C, Murphy CJ, Cheng Z, Hopkins BD, et al. Fenofibrate prevents skeletal muscle loss in mice with lung cancer. Proc Natl Acad Sci USA. (2018) 115:E743-52. doi: 10.1073/pnas.1714703115

153. Maitra R, Thavornwatanayong T, Venkatesh MK, Chandy C, Vachss D, Augustine T, et al. Development and characterization of a genetic mouse model of KRAS mutated colorectal cancer. Int J Mol Sci. (2019) 20:E5677. doi: $10.3390 /$ ijms 20225677

154. Delitto D, Pham K, Vlada AC, Sarosi GA, Thomas RM, Behrns KE, et al. Patient-derived xenograft models for pancreatic adenocarcinoma demonstrate retention of tumor morphology through incorporation of murine stromal elements. Am J Pathol. (2015) 185:1297-303. doi: 10.1016/j.ajpath.2015.01.016

155. Pham K, Delitto D, Knowlton AE, Hartlage ER, Madhavan R, Gonzalo DH, et al. Isolation of pancreatic cancer cells from a patient-derived xenograft model allows for practical expansion and preserved heterogeneity in culture. Am J Pathol. (2016) 186:1537-46. doi: 10.1016/j.ajpath.2016.02.009

156. Go KL, Delitto D, Judge SM, Gerber MH, George TJ Jr, Behrns $\mathrm{KE}$, et al. Orthotopic patient-derived pancreatic cancer xenografts engraft into the pancreatic parenchyma, metastasize, and induce muscle wasting to recapitulate the human disease. Pancreas. (2017) 46:813-9. doi: 10.1097/MPA.0000000000000843

157. Michaelis KA, Norgard MA, Zhu X, Levasseur PR, Sivagnanam S, Liudahl SM, et al. Publisher correction: the TLR7/8 agonist R848 remodels tumor and host responses to promote survival in pancreatic cancer. Nat Commun. (2019) 10:5257. doi: 10.1038/s41467-019-13151-z

158. Sadeghi M, Keshavarz-Fathi M, Baracos V, Arends J, Mahmoudi M, Rezaei N. Cancer cachexia: diagnosis, assessment, and treatment. Crit Rev Oncol Hematol. (2018) 127:91-104. doi: 10.1016/j.critrevonc.2018.05.006

159. Aversa Z, Costelli P, Muscaritoli M. Cancer-induced muscle wasting: latest findings in prevention and treatment. Ther Adv Med Oncol. (2017) 9:369-82. doi: $10.1177 / 1758834017698643$

160. Anderson LJ, Albrecht ED, Garcia JM. Erratum to: update on management of cancer-related cachexia. Curr Oncol Rep. (2017) 19:22. doi: 10.1007/s11912-017-0595-4

161. Jatoi A, Dakhil SR, Nguyen PL, Sloan JA, Kugler JW, Rowland KM Jr, et al. A placebo-controlled double blind trial of etanercept for the cancer anorexia/weight loss syndrome: results from $\mathrm{N} 00 \mathrm{Cl}$ from the North Central Cancer Treatment Group. Cancer. (2007) 110:1396-403. doi: $10.1002 /$ cncr.22944
162. Gordon JN, Trebble TM, Ellis RD, Duncan HD, Johns T, Goggin PM. Thalidomide in the treatment of cancer cachexia: a randomised placebo controlled trial. Gut. (2005) 54:540-5. doi: 10.1136/gut.2004.047563

163. Mantovani G. Randomised phase III clinical trial of 5 different arms of treatment on 332 patients with cancer cachexia. Eur Rev Med Pharmacol Sci. (2010) 14:292-301.

164. Yennurajalingam S, Willey JS, Palmer JL, Allo J, Del Fabbro E, Cohen $\mathrm{EN}$, et al. The role of thalidomide and placebo for the treatment of cancer-related anorexia-cachexia symptoms: results of a double-blind placebo-controlled randomized study. J Palliat Med. (2012) 15:1059-64. doi: 10.1089/jpm.2012.0146

165. Mehrzad V, Afshar R, Akbari M. Pentoxifylline treatment in patients with cancer cachexia: a double-blind, randomized, placebo-controlled clinical trial. Adv Biomed Res. (2016) 5:60. doi: 10.4103/2277-9175.179182

166. Goldberg RM, Loprinzi CL, Mailliard JA, O’Fallon JR, Krook JE, Ghosh C, et al. Pentoxifylline for treatment of cancer anorexia and cachexia? A randomized, double-blind, placebo-controlled trial. J Clin Oncol. (1995) 13:2856-9. doi: 10.1200/JCO.1995.13.11.2856

167. Jatoi A, Ritter HL, Dueck A, Nguyen PL, Nikcevich DA, Luyun RF, et al. A placebo-controlled, double-blind trial of infliximab for cancerassociated weight loss in elderly and/or poor performance non-small cell lung cancer patients. (N01C9). Lung Cancer. (2010) 68:234-9. doi: 10.1016/j.lungcan.2009.06.020

168. Clarke SJ, Smith JT, Gebbie C, Sweeney C, Olszewski N. A phase I, pharmacokinetic. (PK), and preliminary efficacy assessment of ALD518, a humanized anti-IL-6 antibody, in patients with advanced cancer. J Clin Oncol. (2009) 27:3025. doi: 10.1200/jco.2009.27.15_suppl.3025

169. Rigas JR, Schuster M, Orlov SV, Milovanovic B, Prabhash K, Smith JT, et al. Efect of ALD518, a humanized anti-IL-6 antibody, on lean body mass loss and symptoms in patients with advanced non-small cell lung cancer. (NSCLC): results of a phase II randomized, double-blind safety and efficacy trial. J Clin Oncol. (2010) 28:7622. doi: 10.1200/jco.2010.28. 15_suppl.7622

170. Bekaii-Saab T, Phelps MA, Li X, Saji M, Goff L, Kauh JSW, et al. Multiinstitutional phase II study of selumetinib in patients with metastatic biliary cancers. J Clin Oncol. (2011) 29:2357-63. doi: 10.1200/JCO.2010.33.9473

171. Hong DS, Hui D, Bruera E, Janku F, Naing A, Falchook GS, et al. MABp1, a first-in-class true human antibody targeting interleukin- $1 \alpha$ in refractory cancers: an open-label, phase 1 dose-escalation and expansion study. Lancet Oncol. (2014) 15:656-66. doi: 10.1016/S1470-2045(14) 70155-X

172. Hickish T, Andre T, Wyrwicz L, Saunders M, Sarosiek T, Kocsis J, et al. MABp1 as a novel antibody treatment for advanced colorectal cancer: a randomised, double-blind, placebo-controlled, phase 3 study. Lancet Oncol. (2017) 18:192-201. doi: 10.1016/S1470-2045(17)30006-2

173. Lai V, George J, Richey L, Kim HJ, Cannon T, Shores C, et al. Results of a pilot study of the effects of celecoxib on cancer cachexia in patients with cancer of the head, neck, and gastrointestinal tract. Head Neck. (2008) 30:67-74. doi: 10.1002/hed.20662

174. Mantovani G, Macciò A, Madeddu C, Serpe R, Antoni G, Massa E, et al. Phase II nonrandomized study of the efficacy and safety of COX-2 inhibitor celecoxib on patients with cancer cachexia. J Mol Med. (2010) 88:85-92. doi: 10.1007/s00109-009-0547-z

175. Jameson GS, Von Hoff DD, Weiss GJ, Richards DA, Smith DA, Becerra C, et al. Safety of the antimyostatin monoclonal antibody LY2495655 in healthy subjects and patients with advanced cancer. J Clin Oncol. (2012) 30:2516. doi: 10.1200/jco.2012.30.15_suppl.2516

176. Golan T, Geva R, Richards D, Madhusudan S, Lin BK, Wang HT, et al. LY2495655, an antimyostatin antibody, in pancreatic cancer: a randomized, phase 2 trial. J Cachexia Sarcopenia Muscle. (2018) 9:871-9. doi: $10.1002 /$ jcsm. 12331

177. Padhi D, Higano CS, Shore ND, Sieber P, Rasmussen E, Smith MR. Pharmacological inhibition of myostatin and changes in lean body mass and lower extremity muscle size in patients receiving androgen deprivation therapy for prostate cancer. J Clin Endocrinol Metab. (2014) 99:E1967-75. doi: 10.1210/jc.2014-1271

178. Ruiz Garcia V, López-Briz E, Carbonell Sanchis R, Gonzalvez Perales JL, Bort-Marti S. Megestrol acetate for treatment of 
anorexia-cachexia syndrome. Cochrane Database Syst Rev. (2013) CD004310. doi: 10.1002/14651858.CD004310.pub3

179. Madeddu C, Macciò A, Panzone F, Tanca FM, Mantovani G. Medroxyprogesterone acetate in the management of cancer cachexia. Expert Opin Pharmacother. (2009) 10:1359-66. doi: 10.1517/14656560902960162

180. Hiura Y, Takiguchi S, Yamamoto K, Takahashi T, Kurokawa Y, Yamasaki M, et al. Effects of ghrelin administration during chemotherapy with advanced esophageal cancer patients: a prospective, randomized, placebo-controlled phase 2 study. Cancer. (2012) 118:4785-94. doi: 10.1002/cncr.27430

181. Temel JS, Abernethy AP, Currow DC, Friend J, Duus EM, Yan $\mathrm{Y}$, et al. Anamorelin in patients with non-small-cell lung cancer and cachexia. (ROMANA 1 and ROMANA 2): results from two randomised, double-blind, phase 3 trials. Lancet Oncol. (2016) 17:519-31. doi: 10.1016/S1470-2045(15)00558-6

182. Currow D, Temel JS, Abernethy A, Milanowski J, Friend J, Fearon KC. ROMANA 3: a phase 3 safety extension study of anamorelin in advanced non-small-cell lung cancer. (NSCLC) patients with cachexia. Ann Oncol. (2017) 28:1949-56. doi: 10.1093/annonc/mdx192

183. Cannabis-In-Cachexia-Study-Group, Strasser F, Luftner D, Possinger K, Ernst G, Ruhstaller T, et al. Comparison of orally administered cannabis extract and delta-9-tetrahydrocannabinol in treating patients with cancer-related anorexia-cachexia syndrome: a multicenter, phase III, randomized, double-blind, placebo-controlled clinical trial from the Cannabis-In-Cachexia-Study-Group. J Clin Oncol. (2006) 24:3394-400. doi: 10.1200/JCO.2005.05.1847

184. Brisbois TD, de Kock IH, Watanabe SM, Mirhosseini M, Lamoureux DC, Chasen M, et al. Delta-9-tetrahydrocannabinol may palliate altered chemosensory perception in cancer patients: results of a randomized, double-blind, placebo-controlled pilot trial. Ann Oncol. (2011) 22:2086-93. doi: 10.1093/annonc/mdq727

185. Bar-Sela G, Zalman D, Semenysty V, Ballan E. The effects of dosage-controlled cannabis capsules on cancer-related cachexia and anorexia syndrome in advanced cancer patients: pilot study. Integr Cancer Ther. (2019) 18:1534735419881498. doi: 10.1177/153473541 9881498

186. Turcott JG, Del Rocío Guillen Núñez M, Flores-Estrada D, Oñate-Ocaña LF, Zatarain-Barrón ZL, Barrón F, et al. The effect of nabilone on appetite, nutritional status, and quality of life in lung cancer patients: a randomized, double-blind clinical trial. Support Care Cancer. (2018) 26:3029-38. doi: 10.1007/s00520-018-4154-9

187. Lindholm E, Daneryd P, Körner U, Hyltander A, Fouladiun M, Lundholm K. Effects of recombinant erythropoietin in palliative treatment of unselected cancer patients. Clin Cancer Res. (2004) 10:6855-64. doi: 10.1158/1078-0432.CCR-04-0373

188. Bayliss TJ, Smith JT, Schuster M, Dragnev KH, Rigas JR. A humanized antiIL-6 antibody. (ALD518) in non-small cell lung cancer. Expert Opin Biol Ther. (2011) 11:1663-8. doi: 10.1517/14712598.2011.627850

189. Tai Y-T, Fulciniti M, Hideshima T, Song W, Leiba M, Li X-F, et al. Targeting MEK induces myeloma-cell cytotoxicity and inhibits osteoclastogenesis. Blood. (2007) 110:1656-63. doi: 10.1182/blood-2007-03-0 81240

190. Harrison C, Kiladjian J-J, Al-Ali HK, Gisslinger H, Waltzman R, Stalbovskaya V, et al. JAK inhibition with ruxolitinib versus best available therapy for myelofibrosis. N Engl J Med. (2012) 366:787-98. doi: 10.1056/NEJMoa1110556

191. Gramignano G, Lusso MR, Madeddu C, Massa E, Serpe R, Deiana $\mathrm{L}$, et al. Efficacy of l-carnitine administration on fatigue, nutritional status, oxidative stress, and related quality of life in 12 advanced cancer patients undergoing anticancer therapy. Nutrition. (2006) 22:136-45. doi: 10.1016/j.nut.2005.06.003

192. Madeddu C, Dessì M, Panzone F, Serpe R, Antoni G, Cau MC, et al. Randomized phase III clinical trial of a combined treatment with carnitine + celecoxib \pm megestrol acetate for patients with cancer-related anorexia/cachexia syndrome. Clin Nutr. (2012) 31:176-82. doi: 10.1016/j.clnu.2011.10.005

193. Pedersen BK, Febbraio MA. Muscle as an endocrine organ: focus on muscle-derived interleukin-6. Physiol Rev. (2008) 88:1379-406. doi: $10.1152 /$ physrev. 90100.2007
194. Schnyder S, Handschin C. Skeletal muscle as an endocrine organ: PGC-1 $\alpha$, myokines and exercise. Bone. (2015) 80:115-25. doi: 10.1016/j.bone.2015.02.008

195. Manole E, Ceafalan LC, Popescu BO, Dumitru C, Bastian AE. Myokines as possible therapeutic targets in cancer cachexia. J Immunol Res. (2018) 2018:8260742. doi: 10.1155/2018/8260742

196. Lach-Trifilieff E, Minetti GC, Sheppard K, Ibebunjo C, Feige JN, Hartmann $\mathrm{S}$, et al. An antibody blocking activin type II receptors induces strong skeletal muscle hypertrophy and protects from atrophy. Mol Cell Biol. (2014) 34:606-18. doi: 10.1128/MCB.01307-13

197. Mantovani G, Macciò A, Lai P, Massa E, Ghiani M, Santona MC. Cytokine involvement in cancer anorexia/cachexia: role of megestrol acetate and medroxyprogesterone acetate on cytokine downregulation and improvement of clinical symptoms. Crit Rev Oncog. (1998) 9:99-106. doi: 10.1615/CritRevOncog.v9.i2.10

198. Yeh SS, Wu SY, Levine DM, Parker TS, Olson JS, Stevens MR, et al. The correlation of cytokine levels with body weight after megestrol acetate treatment in geriatric patients. J Gerontol A Biol Sci Med Sci. (2001) 56:M4854. doi: 10.1093/gerona/56.1.M48

199. Nanjappa S, Thai C, Shah S, Snyder M. Pharmacy report: megestrol acetate-induced adrenal insufficiency. Cancer Control. (2016) 23:167-9. doi: $10.1177 / 107327481602300212$

200. Wen H-S, Li X, Cao Y-Z, Zhang C-C, Yang F, Shi Y-M, et al. Clinical studies on the treatment of cancer cachexia with megestrol acetate plus thalidomide. Chemotherapy. (2012) 58:461-7. doi: 10.1159/000346446

201. Khatib MN, Gaidhane A, Gaidhane S, Quazi ZS. Ghrelin as a promising therapeutic option for cancer cachexia. Cell Physiol Biochem. (2018) 48:217288. doi: $10.1159 / 000492559$

202. Al Massadi O, López M, Tschöp M, Diéguez C, Nogueiras R. Current Understanding of the hypothalamic ghrelin pathways inducing appetite and adiposity. Trends Neurosci. (2017) 40:167-80. doi: 10.1016/j.tins.2016.12.003

203. Ali S, Chen J-A, Garcia JM. Clinical development of ghrelin axis-derived molecules for cancer cachexia treatment. Curr Opin Support Palliat Care. (2013) 7:368-75. doi: 10.1097/SPC.0000000000000012

204. Pietra C, Takeda Y, Tazawa-Ogata N, Minami M, Yuanfeng X, Duus $\mathrm{EM}$, et al. Anamorelin $\mathrm{HCl}$ (ONO-7643), a novel ghrelin receptor agonist, for the treatment of cancer anorexia-cachexia syndrome: preclinical profile. J Cachexia Sarcopenia Muscle. (2014) 5:329-37. doi: 10.1007/s13539-014-0159-5

205. Garcia JM, Polvino WJ. Effect on body weight and safety of RC1291, a novel, orally available ghrelin mimetic and growth hormone secretagogue: results of a phase I, randomized, placebo-controlled, multiple-dose study in healthy volunteers. Oncologist. (2007) 12:594-600. doi: 10.1634/theoncologist.12-5-594

206. Currow DC, Skipworth RJ. The emerging role of anamorelin hydrochloride in the management of patients with cancer anorexia-cachexia. Fut Oncol. (2017) 13:1767-83. doi: 10.2217/fon-2017-0141

207. Ligresti A, De Petrocellis L, Di Marzo V. From phytocannabinoids to cannabinoid receptors and endocannabinoids: pleiotropic physiological and pathological roles through complex pharmacology. Physiol Rev. (2016) 96:1593-659. doi: 10.1152/physrev.00002.2016

208. Penna F, Busquets S, Toledo M, Pin F, Massa D, López-Soriano FJ, et al. Erythropoietin administration partially prevents adipose tissue loss in experimental cancer cachexia models. J Lipid Res. (2013) 54:3045-51. doi: 10.1194/jlr.M038406

209. Kanzaki M, Soda K, Gin PT, Kai T, Konishi F, Kawakami M. Erythropoietin attenuates cachectic events and decreases production of interleukin-6, a cachexia-inducing cytokine. Cytokine. (2005) 32:234-9. doi: 10.1016/j.cyto.2005.10.002

210. Fukawa T, Yan-Jiang BC, Min-Wen JC, Jun-Hao ET, Huang D, Qian C$\mathrm{N}$, et al. Excessive fatty acid oxidation induces muscle atrophy in cancer cachexia. Nat Med. (2016) 22:666-71. doi: 10.1038/nm.4093

211. Auger C, Knuth CM, Abdullahi A, Samadi O, Parousis A, Jeschke MG. Metformin prevents the pathological browning of subcutaneous white adipose tissue. Mol Metab. (2019) 29:12-23. doi: 10.1016/j.molmet.2019.08.011

212. Tseng Y-C, Kulp SK, Lai I-L, Hsu E-C, He WA, Frankhouser DE, et al. Preclinical investigation of the novel histone deacetylase inhibitor AR-42 
in the treatment of cancer-induced cachexia. J Natl Cancer Inst. (2015) 107:djv274. doi: 10.1093/jnci/djv274

213. Flint TR, Janowitz T, Connell CM, Roberts EW, Denton AE, Coll AP, et al. Tumor-induced IL-6 reprograms host metabolism to suppress anti-tumor immunity. Cell Metab. (2016) 24:672-84. doi: 10.1016/j.cmet.2016.10.010

214. Beharry AW, Sandesara PB, Roberts BM, Ferreira LF, Senf SM, Judge AR. HDAC1 activates FoxO and is both sufficient and required for skeletal muscle atrophy. J Cell Sci. (2014) 127:1441-53. doi: 10.1242/jcs.136390

215. Gao W, Xiong Y, Li Q, Yang H. Inhibition of toll-like receptor signaling as a promising therapy for inflammatory diseases: a journey from molecular to nano therapeutics. Front Physiol. (2017) 8:508. doi: $10.3389 /$ fphys.2017.00508

216. Chansrichavala P, Chantharaksri U, Sritara P, Ngaosuwankul N, Chaiyaroj SC. Atorvastatin affects TLR4 clustering via lipid raft modulation. Int Immunopharmacol. (2010) 10:892-9. doi: 10.1016/j.intimp.2010.04.027

217. Adams S, Kozhaya L, Martiniuk F, Meng T-C, Chiriboga L, Liebes L, et al. Topical TLR7 agonist imiquimod can induce immune-mediated rejection of skin metastases in patients with breast cancer. Clin Cancer Res. (2012) 18:6748-57. doi: 10.1158/1078-0432.CCR-12-1149

218. Zahm CD, Colluru VT, McIlwain SJ, Ong IM, McNeel DG. TLR Stimulation during T-cell activation lowers PD-1 expression on CD8 T cells. Cancer Immunol Res. (2018) 6:1364-74. doi: 10.1158/2326-6066.CIR-18-0243

Conflict of Interest: The authors declare that the research was conducted in the absence of any commercial or financial relationships that could be construed as a potential conflict of interest.

Copyright (c) 2020 Marceca, Londhe and Calore. This is an open-access article distributed under the terms of the Creative Commons Attribution License (CC BY). The use, distribution or reproduction in other forums is permitted, provided the original author(s) and the copyright owner(s) are credited and that the original publication in this journal is cited, in accordance with accepted academic practice. No use, distribution or reproduction is permitted which does not comply with these terms. 